\title{
Recommendations on the use of exercise testing in clinical practice
}

\author{
P. Palange*, S.A. Ward" , K-H. Carlsen`, R. Casaburi', C.G. Gallagher ${ }^{\S}$, R. Gosselink ${ }^{f}$, \\ D.E. O’Donnell**, L. Puente-Maestu"\#, A.M. Schols ${ }^{4}$, S. Singh ${ }^{++}$and B.J. Whipp ${ }^{\#}$
}

ABSTRACT: Evidence-based recommendations on the clinical use of cardiopulmonary exercise testing (CPET) in lung and heart disease are presented, with reference to the assessment of exercise intolerance, prognostic assessment and the evaluation of therapeutic interventions (e.g. drugs, supplemental oxygen, exercise training). A commonly used grading system for recommendations in evidence-based guidelines was applied, with the grade of recommendation ranging from $A$, the highest, to $D$, the lowest.

For symptom-limited incremental exercise, CPET indices, such as peak $\mathrm{O}_{2}$ uptake $\left(\mathrm{V}^{\prime} \mathrm{O}_{2}\right), \mathrm{V}^{\prime} \mathrm{O}_{2}$ at lactate threshold, the slope of the ventilation- $\mathrm{CO}_{2}$ output relationship and the presence of arterial $\mathrm{O}_{2}$ desaturation, have all been shown to have power in prognostic evaluation. In addition, for assessment of interventions, the tolerable duration of symptom-limited high-intensity constant-load exercise often provides greater sensitivity to discriminate change than the classical incremental test. Field-testing paradigms (e.g. timed and shuttle walking tests) also prove valuable.

In turn, these considerations allow the resolution of practical questions that often confront the clinician, such as: 1) "When should an evaluation of exercise intolerance be sought?"; 2) "Which particular form of test should be asked for?"; and 3) "What cluster of variables should be selected when evaluating prognosis for a particular disease or the effect of a particular intervention?"

KEYWORDS: Cardiopulmonary exercise testing, evaluation of interventions, exercise testing, prognosis, walking tests

$\mathbf{T}$ he purpose of this document is to present recommendations on the clinical use of exercise testing in patients with cardiopulmonary disease, with particular emphasis on the evidence base for the functional evaluation, prognosis and assessment of interventions. While the scope of the document is broad, consideration will focus only on those indices that have demonstrable predictive power. Supplemental references will therefore be included, where appropriate.

Exercise intolerance can be defined as an inability to complete a required physical task successfully. In one sense, therefore, everyone who exercises has, at some level(s), "exercise intolerance". From a clinical perspective, the issue is whether a patient demonstrates intolerance to a task that normal subjects would find tolerable. However, exercise intolerance (often considered in terms of peak oxygen uptake $\left(V^{\prime} \mathrm{O}_{2}\right.$,peak)) in pulmonary and cardiac disease patients cannot be confidently predicted from physiological variables, determined at rest, such as forced expiratory volume in one second (FEV1), pulmonary diffusing capacity for carbon monoxide (DL,CO), ejection fraction (EF) or body mass index (BMI). It is necessary, therefore, to actually assess an individual's exercise intolerance and, where possible, establish its cause(s). This task-specificity imposes technical challenges: the requirement to be able to impose particular work-rate protocols in an accurate and reproducible fashion largely confines assessment to ergometric devices, such as cycle ergometers and treadmills. While these represent a less-than-ideal approximation to the realities of daily exercise, they provide a precise and controlled focus for assessing the

\section{AFFILIATIONS}

*Servizio di Fisiopatologia Respiratoria, Dipartimento di Medicina Clinica, University of Rome "La Sapienza", Rome, Italy. "Institute of Membrane and Systems Biology, University of Leeds, Leeds, and

"Dept of Respiratory Medicine Glenfield Hospital, Leicester, UK. "Voksentoppen Research Institute and Children's National Hospital of Asthma, Allergy and Chronic Lung Diseases, University of Oslo, Oslo, Norway.

+Rehabilitation Clinical Trials Center, Los Angeles Biomedical Research Institute, Harbor-UCLA Medical Center, Torrance, CA, USA.

${ }^{\S}$ Dept of Respiratory Medicine and the National Referral Centre for Adult Cystic Fibrosis, St Vincent's University Hospital, Dublin, Ireland. ${ }^{f}$ Respiratory Rehabilitation and Respiratory Division, University Hospital Gasthuisberg, Leuven, Belgium.

**Respiratory Investigation Unit, Department of Medicine, Queen's University, Kingston, ON, Canada. \#\# Servicio de Neumología, Hospital General Universitario Gregorio Marañon, Madrid, Spain. "Dept of Respiratory Medicine, University Hospital Maastricht, Maastricht, The Netherlands.

CORRESPONDENCE

P. Palange: Dipartimento di Medicina Clinica, University of Rome "La Sapienza", v.le Università 37, 00185 Rome, Italy. Fax: 39064940421 E-mail: paolo.palange@uniroma1.it

Received:

April 042006

Accepted after revision: August 162006 
appropriateness of the interaction among the contributing physiological support systems.

Cardiopulmonary exercise testing (CPET) should be considered the gold standard for evaluating the causes of exercise intolerance in patients with pulmonary and cardiac disease, and is based on the principle that system failure typically occurs while the system (e.g. muscle-energetic, cardiovascular or pulmonary) is under stress. CPET comprises the imposition of symptom-limited incremental exercise, commonly in combination with comprehensive breath-by-breath monitoring of cardiopulmonary variables (e.g. $V^{\prime} \mathrm{O}_{2}$, pulmonary $\mathrm{CO}_{2}$ output $\left(V^{\prime} \mathrm{CO}_{2}\right)$, minute ventilation $\left(V^{\prime} \mathrm{E}\right)$, cardiac frequency $\left.(f \mathrm{C})\right)$, perceptual responses (e.g. dyspnoea, leg discomfort) and, as needed, measurements such as exercise-related arterial oxygen desaturation, dynamic hyperinflation and limb-muscle strength. Thus, the support systems are "forced", normally over their tolerable range, in a controlled way that allows key system responses to be expressed relative to an appropriate frame of reference (e.g. $V^{\prime} \mathrm{E}$ being expressed relative to $V^{\prime} \mathrm{CO}_{2}$ ) and indices of aerobic function (e.g. lactate threshold $(\theta \mathrm{L})$, $V^{\prime} \mathrm{O}_{2}$,peak) to be discriminated confidently. Previous European Respiratory Society and American Thoracic Society (ATS)/ American College of Chest Physicians statements have provided useful recommendations on the standardisation of CPET in clinical practice [1-3].

While a wide variety of tests is available, each being more or less suitable as a stressor of a particular component of a patient's pathophysiology, the appropriateness of the integrated physiological-system response is best studied (certainly, for initial exercise evaluation) by means of a symptom-limited incremental test. This is typically established by means of a progressive increase in work-rate by a small fixed increment at a fixed frequency (e.g. each minute or less), in a "staircase" fashion, or when work-rate is increased incrementally under computer control as a smooth continuous ramp both with cycle-ergometry [1,3-5] and, more recently, for the treadmill [6]. However, high-intensity constant-load tests are also becoming widely used as, in many instances, they provide a sensitive discrimination of improved function consequent to an intervention.

System function can be well described through a range of appropriately selected responses to incremental and/or highintensity constant-load exercise. These may represent values of variables at certain reference points within the tolerable range of the test or response profiles over selected regions of interest. Assessing the normality, or otherwise, of such system responses requires the investigator to select, and display appropriately, the cluster of response variables that are best reflective of the behaviour of the particular system(s). Discrimination of the magnitude and/or pattern of deviation from the normal response of the age-, sex- and activitymatched "standard" subject can then be attempted, and the magnitude or pattern of abnormality matched with that characteristic of the specific physiological system(s) that is/ are dysfunctional. In some instances, appropriate normal values may not be readily available. In others, values may be modality-dependent (e.g. greater muscle mass involved in treadmill exercise results in a slightly higher $V^{\prime} \mathrm{O}_{2}$, peak).
However, although there is widespread clinical use of CPET, it is not considered to provide a substantial improvement in primary diagnostic power (i.e. with respect to the basic category of abnormality) over more classical clinical tools such as spirometry and electro- and echo-cardiography. What CPET can do, however, is provide considerable "fine tuning" of these considerations, by: 1) revealing specific abnormalities that occur only when support systems are stressed by physical activity (e.g. dynamic hyperinflation in chronic obstructive pulmonary disease (COPD) or increased ventilatory response in chronic heart failure (CHF)); and 2) providing a functional frame of reference for assessing the efficacy of interventions targeted to ameliorate such abnormalities (e.g. bronchodilators for dynamic hyperinflation or vasodilators for heart failure).

With the more recent recognition that improved functional status following an intervention such as exercise training in patients with chronic lung disease does not always manifest itself in appreciable increases in classical performance indices such as $V^{\prime} \mathrm{O}_{2}$,peak, the scope of CPET has been expanded to include laboratory-based high-intensity constant-load exercise paradigms performed to the limit of tolerance (tlim), which can provide a more sensitive frame of reference especially in the context of prognosis and intervention. Field-testing paradigms, such as timed and shuttle walking tests, are also becoming popular, often supported by measurements of variables such as arterial oxygen saturation $\left(S_{p}, \mathrm{O}_{2}\right.$, used here in preference to the more conventional abbreviation $\mathrm{Sa}_{2} \mathrm{O}_{2}$, to reflect the fact that during exercise it is most commonly measured noninvasively using pulse oximetry), $f C$ and exertional symptoms. What is perhaps not so widely recognised is that such tests can be viewed constructively in the context of the "power-duration relationship" for constant-load symptom-limited exercise. Finally, the use of CPET is becoming more widespread both prognostically and for the evaluation of interventions such as oxygen supplementation, exercise-based rehabilitation and drug therapies.

This document is therefore intended to provide the answers to three fundamental questions often faced by clinicians: 1) "When should an evaluation of exercise intolerance be sought?"; 2) "Which particular form of test should be asked for?"; and 3) "What cluster of variables should be selected when evaluating prognosis for a particular disease or the effect of a particular intervention?". This is accomplished through critical evaluation of CPET outcomes in the context of diagnosis, prognosis and pertinent interventions, with the underlying physiological principles being presented in supplementary material online.

\section{UTILITY OF CPET IN DIAGNOSIS AND FUNCTIONAL EVALUATION}

What additional diagnostic and/or prognostic information can be expected to arise from CPET in a particular patient? CPET can: provide an objective measure of exercise capacity; identify the mechanisms limiting exercise tolerance; establish indices of the patient's prognosis; and monitor disease progression and/ or the response to interventions. What CPET cannot uniquely do is affect diagnosis, except in very specific conditions, such as exercise-induced bronchoconstriction and arterial oxygen desaturation. In most instances, the patient to be studied will have already presented with a primary diagnosis. However, 
where CPET can be valuable is in differential diagnosis; for instance, profiles of judiciously selected cardiopulmonary and gas-exchange response can distinguish between pulmonary and cardiac limitations to exercise. The interpretative power of CPET can be strengthened by incorporating additional measurements. In a patient with a primary diagnosis of COPD, for example, these typically include habitual physical activity levels, body mass and composition, muscle strength, exercise-related arterial desaturation, dynamic hyperinflation and exacerbation of symptoms. Importantly, CPET should be viewed as a key adjunct to a previous comprehensive medical evaluation comprising a medical history and examination and, depending on what is suspected, other complementary tests and measurements (e.g. haematocrit, biochemistry, resting electrocardiogram, chest radiography, arterial blood-gas analysis, resting pulmonary function testing). The nature and extent of the medical evaluation prior to exercise testing should be focused on narrowing the range of suspected diseases.

\section{Exercise intolerance}

Measurement of $V^{\prime} \mathrm{O}_{2}$,peak (see section 1.1 and fig. 1, both in supplementary material) is highly reproducible in healthy asymptomatic subjects who are well motivated during the exercise test. This has also been shown to be the case in situations where exercise is symptom-limited [7-10], which is important in contexts such as disability benefits claims or exercise prescription when a patient complains of breathlessness or exercise intolerance. In certain diseases, such as COPD and CHF, where it is preferable that the index of exercise intolerance relates more closely to activities of daily living, walking tests such as the 6-min walking test (6-MWT) [11, 12] are commonly used. As is the case for CPET, reproducibility requires that standardised procedures are adopted.

\section{Causes of exercise intolerance}

The causes of exercise intolerance can broadly be classed as "central" ("Could, but won't") and "peripheral" ("Would, but can' $t$ "). The classical criterion for defining exercise intolerance and classifying degrees of impairment is $V^{\prime} \mathrm{O}_{2}$,peak standardised by body mass [13]. As factors such as habitual physical activity, age, sex and height influence $V^{\prime} \mathrm{O}_{2}$,peak (see supplementary material, 1.1) and distance walked on the 6-MWT (6MWD) [14-16], it is recommended that the normalcy (or otherwise) of exercise capacity be judged relative to reference values for matched healthy populations, taking into account not only body mass but, in certain conditions, also fat-free mass (see supplementary material, 1.1). Values $>1.96$ times the SD should be considered abnormal with a confidence of $95 \%$.Values $<40 \%$ predicted indicate severe impairment [17].

CPET in the identification of the causes of exercise intolerance There are several CPET response patterns that are not diseasespecific but nonetheless point to particular sites of system dysfunction, thereby narrowing the differential diagnosis (c.f. fig. 2 in supplementary material). The absence of these response patterns can be taken as evidence against a significant involvement of these systems in exercise limitation. Although the exact mechanisms of exercise limitation in individuals without known disease are difficult to establish, ventilatory limitation is usually unlikely as there is still a significant breathing reserve at peak exercise (see supplementary material, 1.6) [17]. Furthermore, a decreased arterial carbon dioxide tension $\left(\mathrm{Pa}_{1} \mathrm{CO}_{2}\right)$ at end-exercise implies respiratory compensation for metabolic acidosis (see supplementary material, 1.3 and 1.5) as, despite some widening of the alveolar-arterial oxygen difference $\left(\mathrm{PA}-\mathrm{a}, \mathrm{O}_{2}\right)$, arterial oxygen tension $\left(\mathrm{Pa}_{\mathrm{a}} \mathrm{O}_{2}\right)$ and $\mathrm{Sp}_{\mathrm{p}} \mathrm{O}_{2}$ are not appreciably different from resting values [18]. With good subject effort, if $V^{\prime} \mathrm{O}_{2}$,peak is above the lower limit of the 95\% confidence interval (i.e. "normal" $V^{\prime} \mathrm{O}_{2}$,peak) and the subject indicates that either dyspnoea or leg fatigue was the reason for stopping exercise, then the subject is frequently deemed to have a normal exercise tolerance. This scenario would effectively exclude significant COPD or interstitial lung disease (ILD) [19, 20], CHF [21] and pulmonary vascular disorders (PVD) [22] as causes of the exercise intolerance. However, while the finding of a normal $V^{\prime} \mathrm{O}_{2}$,peak may be helpful in providing reassurance to the patient and in limiting subsequent testing, it is important to recognise that normal in this context actually means "what is to be expected for relatively sedentary subjects" (i.e. characteristic of the group from which the normal value derives). So a normal $V^{\prime} \mathrm{O}_{2}$,peak in a subject with a high activity level, or one who has previously been highly fit, should not necessarily be viewed as reflecting the absence of an abnormality.

For patients with unexplained exercise intolerance for whom initial test results (e.g. spirometry and echocardiography) are non-diagnostic, CPET may represent a useful tool in identifying whether the exercise intolerance is due to abnormalities in the oxygen transport pathway (extending from atmospheric air to the mitochondria in muscle), deconditioning or psychological factors (hyperventilation, panic, anxiety syndromes, etc.). Response patterns may not be diagnostic of specific aetiology but, together with previous medical evaluation, they can help to direct further diagnostic testing [4, 23-26].

\section{Abnormal oxygen delivery}

This term encompasses several heterogeneous conditions that have in common a reduced systemic oxygen delivery (i.e. the product of cardiac output and arterial oxygen content) during exercise, relative to metabolic demands. These are characterised by a low $V^{\prime} \mathrm{O}_{2}$, peak and low $\theta \mathrm{L}$ (see supplementary material, 1.1 and 1.3). $f C$ reserve is also frequently low, although if symptoms force the patient to quit early, $f C$ reserve will be high (see supplementary material, 1.4). In most cases, peak $\mathrm{O}_{2}$ pulse is low and the $f \mathrm{C}-V^{\prime} \mathrm{O}_{2}$ slope is steep [27-29] and, with significant systolic or diastolic heart failure, the $\mathrm{O}_{2}$ pulse plateaus early in the test (see supplementary material, fig. 4) [30]. The finding of $\mathrm{O}_{2}$ pulse increasing normally until a point and then decreasing, with a corresponding increase in the $f \mathrm{C}-$ $V^{\prime} \mathrm{O}_{2}$ slope, is relatively specific to coronary artery disease [31].

\section{Ventilatory limitation to exercise}

Ventilatory limitation at peak exercise, which is usually observed in obstructive lung diseases (see fig. 6 in supplementary material) and may also be seen in restrictive lung diseases, is judged to occur when $V^{\prime} \mathrm{E} /$ maximum voluntary ventilation (MVV) exceeds $85 \%$ [17], particularly if respiratory compensation for metabolic acidosis is not evident, i.e. $\mathrm{Pa}, \mathrm{CO}_{2}$ being increased [32] or normal with a high dead space fraction of the breath (dead volume/tidal volume; $V \mathrm{D} / V \mathrm{~T}$ ). A low breathing reserve may also be seen in endurance ahletes and fit 
elderly people, for whom $V^{\prime} \mathrm{O}_{2}$,peak is above the normal agematched range (see supplementary material, 1.6).

\section{Abnormal ventilatory control}

It is important to emphasise that the profile of ventilatory response to exercise cannot be predicted from resting lung function; it must be measured. The appropriate frame of reference for $V^{\prime} \mathrm{E}$ is $V^{\prime} \mathrm{CO}_{2}$ (see supplementary material, 1.5), and it will emerge that the $V^{\prime} \mathrm{E}-V^{\prime} \mathrm{CO}_{2}$ slope and the ventilatory equivalent for $\mathrm{CO}_{2}\left(V^{\prime} \mathrm{E} / V^{\prime} \mathrm{CO}_{2}\right)$ at $\theta \mathrm{L}$ are important in diagnosis, prognosis and evaluation of interventions. Abnormal ventilatory control during exercise is defined as an inappropriately high (hyperventilation, i.e. low carbon dioxide tension $\left(\mathrm{PCO}_{2}\right)$ set-point) or low (hypoventilation, i.e. high $\mathrm{PCO}_{2}$ set-point) $V^{\prime} \mathrm{E}-V^{\prime} \mathrm{CO}_{2}$ slope. The defect may be primary (i.e. not attributable to any specific disease or known mechanism) or secondary (i.e. secondary to hypoxia, or other influences in respiratory or cardiac diseases that can stimulate $V^{\prime} \mathrm{E}$ ).

In primary hyperventilation, there is a marked hyperventilation at rest with metabolic compensation being more or less complete. The hyperventilation is maintained during exercise, i.e. with abnormally large increases in $V^{\prime} \mathrm{E}$ and an elevated $V^{\prime} \mathrm{E}-$ $V^{\prime} \mathrm{CO}_{2}$ slope [33-35]. However, as an increased $V^{\prime} \mathrm{E}-V^{\prime} \mathrm{CO}_{2}$ slope can reflect an increased $V \mathrm{D} / V \mathrm{~T}$ as well as a reduced $\mathrm{PCO}_{2}$ setpoint, simultaneous $\mathrm{Pa}, \mathrm{CO}_{2}$ monitoring is needed to rule out the former. $\mathrm{Pa}_{1} \mathrm{CO}_{2}$ typically remains depressed during exercise [35], although there have been reports that $\mathrm{Pa}_{1} \mathrm{CO}_{2}$ may increase towards normal levels when exercise is intense enough for automatic mechanisms of control to override the presumed corticogenic drive [4]. In some patients, exercise-induced bronchoconstriction (EIB) may be the cause of exercise hyperventilation [36]. In addition, in subjects with normal coronary arteries, hyperventilation during exercise has been associated with ECG changes resembling ischaemia [37].

Secondary hyperventilation during exercise (with a reduced $\left.\mathrm{Pa}, \mathrm{CO}_{2}\right)$ is proposed to result from hypoxaemia-induced stimulation of peripheral (carotid) chemoreceptors, cardiopulmonary mechanoreceptor activity (ILD, PVD) and/or muscle mechano- or chemoreceptor activation (e.g. CHF) [20, 22, 38-43].

Primary hypoventilation is defined as an abnormally low increase in $V^{\prime} \mathrm{E}$ relative to $V^{\prime} \mathrm{CO}_{2}$ (i.e. reduced $V^{\prime} \mathrm{E}-V^{\prime} \mathrm{CO}_{2}$ slope) with $\mathrm{CO}_{2}$ retention in the absence of a recognisable pulmonary disease [44-46]. Secondary hypoventilation is frequently observed in COPD [19, 32], and may also be seen in advanced ILD [20] and neuromuscular diseases [47]. It is important to point out that when exercise hypoventilation occurs in COPD and ILD, $V^{\prime} E$ may, seemingly paradoxically, be higher than normal at a given $V^{\prime} \mathrm{CO}_{2}$ despite $\mathrm{CO}_{2}$ retention; this reflects the influence of an elevated $V \mathrm{D} / V \mathrm{~T}$.

\section{Pulmonary gas exchange abnormalities}

The efficiency of pulmonary gas exchange is conventionally judged by the magnitude of $\mathrm{PA}-\mathrm{a}, \mathrm{O}_{2}$, and knowledge of how this changes during exercise can be useful in evaluating the severity of many lung and heart diseases. The behaviour of $P$ A$\mathrm{a}, \mathrm{O}_{2}$ during exercise cannot be predicted from resting lung function; it has to be measured. Normally $\mathrm{Pa}_{2} \mathrm{O}_{2}$ does not decrease during exercise and $\mathrm{PA}-\mathrm{a}, \mathrm{O}_{2}$ at peak exercise remains below $2.66-3.99 \mathrm{kPa} \quad(20-30 \mathrm{mmHg}) \quad[48,49]$. A $P \mathrm{~A}-\mathrm{a}, \mathrm{O}_{2}$
$>3.99 \mathrm{kPa}(30 \mathrm{mmHg}$ ) at peak exercise is defined as abnormal and is commonly accompanied by arterial desaturation (i.e. $\mathrm{Sp}, \mathrm{O}_{2}<88 \%$ ). $\mathrm{Pa}_{1} \mathrm{O}_{2} \leqslant 7.32 \mathrm{kPa}(55 \mathrm{mmHg})$ is usually considered clinically significant, and may limit exercise tolerance with the potential to endanger the subject. This is seen in most patients with ILD and PVD, in many patients with moderate and severe COPD [50-54], and less frequently in patients with intracardiac left-to-right shunting or chronic heart failure [4]. Interestingly, it can also be seen in elite endurance athletes (see supplementary material, 1.8).

\section{Muscle metabolic dysfunction}

There are many sites within skeletal muscle metabolic pathways whose dysfunction can result in exercise intolerance (reduced $V^{\prime} \mathrm{O}_{2}$,peak and $\theta \mathrm{L}$ ), ranging from routes of substrate delivery and utilisation to energy transformations themselves. The detection of such impairments is beyond the scope of conventional CPET and relies on interventions such as muscle biopsy and noninvasive muscle nuclear magnetic resonance spectroscopy and imaging (the interested reader is referred to [55-58] for further discussion).

As one of the more commonly affected processes is mitochondrial oxygen consumption, in general terms, the exercise response pattern is similar to that for conditions grouped under the heading of abnormal oxygen transport. In the absence of evident cardiopathy, anaemia or carboxyhaemoglobinaemia, muscle myopathic disease is suggested. However, milder forms of myopathy as well as significant muscle deconditioning (see later) may be difficult to differentiate from mild cardiovascular disease. Patients with metabolic myopathies may also present with muscle pain during or after exhausting exercise $[41,43,59]$ or with cramps during exercise (myoadenylate deaminase deficiency) [60].

\section{Deconditioning}

Patients with a sedentary lifestyle may complain of exercise intolerance. Unless the sedentarity is marked, $V^{\prime} \mathrm{O}_{2}$,peak may be normal or only mildly decreased. A cardinal sign of deconditioning is a leftward shift and steepening of the $f \mathrm{C}-V^{\prime} \mathrm{O}_{2}$ relationship and a shallower $\mathrm{O}_{2}$ pulse profile (see supplementary material, 1.4), although peak $f C$ can be normal (if care is taken to motivate the subject during the test) with consequently little or no $f C$ reserve. Because of the low $V^{\prime} \mathrm{O}_{2}$,peak, there is usually significant breathing reserve. $\mathrm{Pa}_{1} \mathrm{O}_{2}$ and $V \mathrm{D} / V \mathrm{~T}$ responses are normal. Deconditioning is often difficult to distinguish from mild heart disease, but if the medical history shows no evidence of disease, it is reasonable attribute the exercise intolerance solely to deconditioning.

\section{Excessive perception of symptoms}

In some individuals with exercise intolerance, the only finding is a disproportionate or exaggerated perception of symptoms (e.g. dyspnoea, leg effort) with no evident physiological abnormality [61]. This condition constitutes a problem in clinical practice often requiring further explanation. CPET is a valuable tool in this regard, providing the clinician with evidence that the patient-perceived symptoms are not due to significant cardiovascular or respiratory disease. It is rare that either healthy subjects or patients with chronic disease score their symptoms (i.e. dyspnoea, leg fatigue) higher than 7 on the 
Borg 10-point scale, especially at peak exercise [62], although in patients with chronic disease the ratios of symptom score $/ V^{\prime} \mathrm{O}_{2}$ and symptom score $/ V^{\prime}$ E may be increased $[23,63]$.

\section{Poor effort}

The assumption underlying CPET is that test termination signifies the expression of physiological system limitation. In rare cases, however, the end-point may be reflective of poor effort ("Could, but won' $t$ "), as, for instance, with malingering [4]. Thus, poor effort is evident in a low $V^{\prime} \mathrm{O}_{2}$,peak with a high $f C$ reserve and breathing reserve. The lactate threshold may not be reached, or may be normal rather than low. Breathing pattern is likely to be atypically irregular (see supplementary material, fig. 2, panel 7), leading to erratic fluctuations in endtidal and arterial $\mathrm{PCO}_{2}$ (see supplementary material, fig. 2, panel 6).

\section{Differential diagnosis}

Exercise testing has been proven to be useful for: distinguishing between normal and abnormal responses to exercise; differentiating between cardiovascular and pulmonary causes of exercise intolerance [1, 64-68]; and identifying disorders of pulmonary gas exchange, certain muscle diseases and psychological disorders [4, 23-25].

Algorithms based on key measurements can be helpful in the identification of the causes that limit exercise tolerance. However, they may fail in the evaluation of early or mild disease as well as combined disease (i.e. cardiac-pulmonary). Furthermore, although several differing interpretative algorithms have been developed, none have been clinically validated. Notably, in one study of 130 consecutive, clinically indicated cardiopulmonary exercise tests that were performed with radial and pulmonary artery catheters in place [69], a widely used, noninvasive cardiopulmonary exercise test diagnostic algorithm [4], unmodified, showed a sensitivity for pulmonary vascular limitation (defined as pulmonary vascular resistance at maximum exercise $>120$ dynes $\cdot \mathrm{sec} \cdot \mathrm{cm}^{-5}$ ) of $79 \%$, a specificity of $75 \%$ and an accuracy of $76 \%$. With some adjustments of branch-point threshold values, specificity and accuracy improved to $88 \%$ and $85 \%$, respectively.

\section{CPET RESPONSE PROFILE IN SPECIFIC DISEASES}

This section considers whether specific patterns of response abnormality have diagnostic power for particular pulmonary (COPD, ILD, primary pulmonary hypertension (PPH), cystic fibrosis $(\mathrm{CF})$ ) and cardiac $(\mathrm{CHF})$ diseases.

\section{Chronic obstructive pulmonary disease}

While the response to incremental exercise may have certain characteristic features, the diagnosis of COPD patients, except in rare exceptions, requires no more than clinical history and spirometry. Exercise testing in such patients, however, is increasingly used for the objective measurement of exercise capacity and for the identification of the causes limiting exercise tolerance that can be eventually be ameliorated or even corrected by specific interventions (e.g. bronchodilators, supplemental oxygen, rehabilitation). In COPD patients, exercise intolerance is multifactorial in origin. Recognised contributory factors include, alone or in combination, exertional symptoms (e.g. dyspnoea, leg fatigue), reduced ventilatory capacity, development of dynamic hyperinflation, peripheral muscle dysfunction and $\mathrm{O}_{2}$ transport abnormalities. These factors are highly interdependent and occur in variable combinations that differ from patient to patient. Importantly, exercise intolerance cannot be predicted in the individual patient from indices of pulmonary and cardiac function at rest [70-73]. $V^{\prime} \mathrm{O}_{2}$,peak obtained with CPET is the best available index of aerobic capacity in COPD, provided that the subject has attained his or her limits (see supplementary material, 1.1), and its measurement is also reasonably reproducible in COPD [74-76].

\section{Ventilatory limitation, ventilatory requirement and dynamic hyperinflation}

In the vast majority of COPD patients, CPET reveals that exercise tolerance is largely limited by the combination of a reduced ventilatory capacity and an increased ventilatory requirement, which exacerbates dyspnoeic sensation. In addition, a heightened perception of leg effort may be a limiting factor in a substantial number of patients, particularly during cycle-ergometer exercise [63, 77]. Importantly, the development of dynamic hyperinflation has been recognised as an important limiting factor responsible for the development of intolerable dyspnoea during exercise (fig. 1; see supplementary material, 1.7) [78]. The increased ventilatory demand in flowlimited patients during exercise gives rise to air trapping and dynamic hyperinflation [32]. The extent of dynamic hyperinflation depends on the degree of expiratory flow limitation, the shape of the maximal expiratory flow-volume loop, the prevailing $V^{\prime} \mathrm{E}$, the breathing pattern at that level of $V^{\prime} \mathrm{E}$, and the degree of resting lung hyperinflation. The decrease in inspiratory capacity (IC) often occurs in association with an increased $\mathrm{Pa}_{\mathrm{a}} \mathrm{CO}_{2}[32,79]$ or a reduced $V \mathrm{~T}[80]$, which strongly suggests that respiratory mechanics are reaching their functional limit. However, the extent of the reduction in IC with exercise in COPD is variable. In a population of 105 patients with moderate-to-severe COPD, IC at end-exercise was reduced by $20 \%$ of its already-reduced resting value [81], as exemplified in figure 1 . In another smaller group of 27 severe COPD patients, a similar reduction was found at the end of high-intensity exercise [80]. Similar changes have also been reported in severe COPD [82].

Other ventilatory abnormalities frequently observed in COPD during exercise are a high $V^{\prime} \mathrm{E}$ for a given $V^{\prime} \mathrm{CO}_{2}$, due to the variable contribution of an increased $V \mathrm{D} / V \mathrm{~T}$ and a reduced $\mathrm{PCO}_{2}$ set-point because of arterial hypoxaemia and premature metabolic acidosis.

\section{Arterial oxygen desaturation during exercise}

The detection of $\mathrm{O}_{2}$ desaturation is an important indication for CEPT in COPD patients since neither the occurrence nor the severity of desaturation during exercise can be predicted readily from resting pulmonary function $[73,83]$. Only in cases when high $D \mathrm{~L}, \mathrm{CO}$ is accompanied by a high resting $\mathrm{Sp}_{\mathrm{p}} \mathrm{O}_{2}$ (i.e. $\geqslant 95 \%$ at sea level) does $D \mathrm{~L}, \mathrm{CO}$ have an elevated negative predictive value [84], but in a large retrospective study, overall sensitivity and specificity, determined by receiver operating curve analysis, were both $75 \%$ with a cut-off point of $62 \%$ pred for DL,CO [85].

Arterial desaturation during exercise is a common feature of advanced COPD $[53,54]$. While desaturation may occur with 


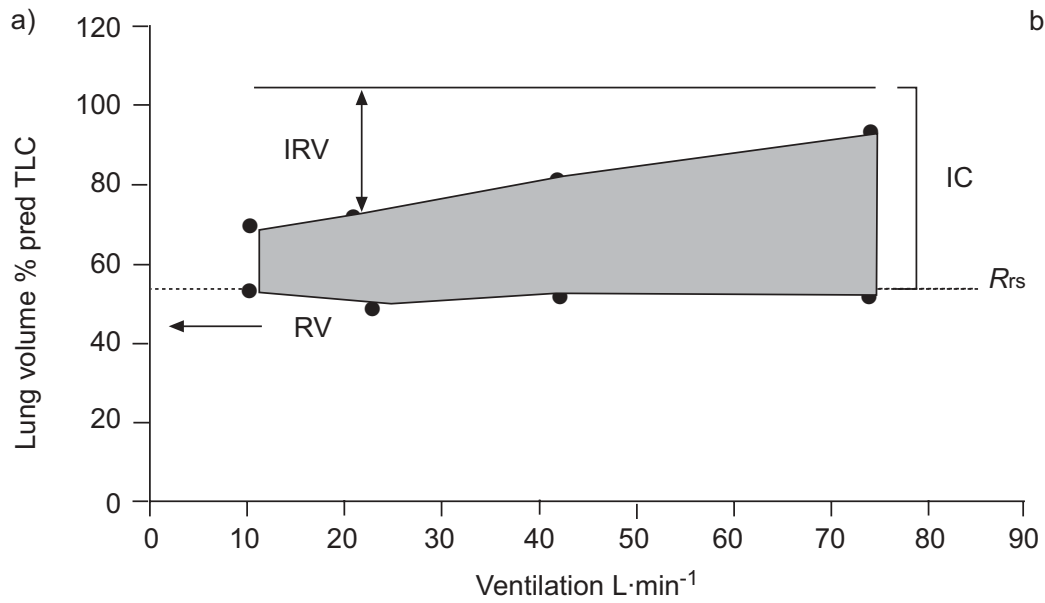

b)

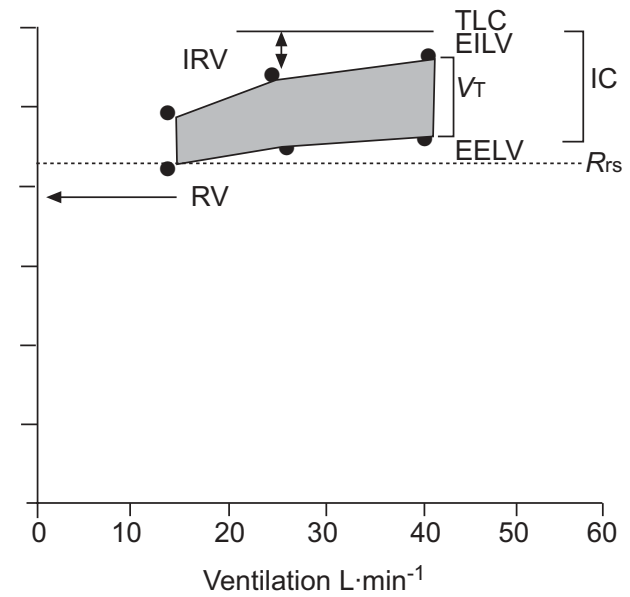

FIGURE 1. Changes in operating lung volumes are shown as ventilation increases with exercise in a) age-matched healthy subjects and b) chronic obstructive pulmonary disease (COPD) patients. End-expiratory lung volume (EELV) increases above the relaxation volume of the respiratory system (Rrs) in COPD, as reflected by a decrease in inspiratory capacity $(\mathrm{IC})$, while EELV in health either remains unchanged or decreases. TLC: total lung capacity; RV: residual volume; IRV: inspiratory reserve volume; EILV: end-inspiratory lung volume; VT: tidal volume. Reproduced from [78] with permission from the publisher.

any type of intense leg exercise, walking either on a treadmill or freely along the ground elicits more hypoxaemia than cycleergometry [54, 86-88]. Any of the standardised walk tests is suitable for diagnosing desaturation [11].

\section{Exercise-induced bronchoconstriction}

EIB, defined as a fall in post-exercise FEV1, should be suspected in any patient who presents with wheezing, cough, chest tightness or dyspnoea during or shortly after exercise. In adults, a challenge test is indicated: in making a diagnosis of EIB in asthmatic patients with a history of breathlessness during or after exertion, particularly in those complaining of symptoms after exercise in spite of presumably adequate treatment; and to determine the effectiveness and optimal dosing of medications prescribed to prevent EIB [83, 89, 90].

Comparisons of exercise challenges for EIB with histamine and methacholine challenges in asthmatic patients show that exercise challenges are consistently less sensitive but more specific than chemical challenges in detecting EIB [91-97]. Many asthmatics $(\sim 30 \%)$ with mild bronchial hyperresponsiveness to chemical stimuli have negative responses to exercise challenges, but there are individuals who have positive responses to exercise challenges and negative responses to histamine or methacholine challenges [98]. Taken together, this information suggests that a positive exercise challenge outcome is relatively specific in identifying clinical asthma, but is somewhat insensitive to the presence of clinically relevant mild bronchial hyperresponsiveness. In this regard, the sensitivity-specificity profile of exercise challenge response resembles that of a histamine or methacholine provocative concentration causing a $20 \%$ fall in FEV1 of 1 or $2 \mathrm{mg} \cdot \mathrm{mL}^{-1}$ [99].

For practical reasons, running on a treadmill is usually preferred for the detection of EIB in children. This enables the use of the muscles most often used in play and other common physical activities, whereas cycling may lead to muscular fatigue at a lower absolute work rate. It has been shown in children that running provokes EIB more easily than cycling, and free running more than running on a treadmill in a laboratory [100]. Running for 6-8 min provokes a greater decrease in post-exercise FEV1 than running for shorter or longer periods, recognising that running on a motor-driven treadmill is particularly useful and easy to standardise [101].

EIB is thought to be caused by increased heat and/or water loss due to increased ventilation during exercise [102, 103]. Standardisation of these factors is thus important in exercise challenge testing. It is recommended that exercise testing for EIB be performed at room temperature $\left(20-22^{\circ} \mathrm{C}\right)$, with a relative humidity of $\sim 40 \%$. When exercise testing is used to monitor EIB with repeated measurements, these environmental factors should be kept constant.

Choice of work-rate is essential to the outcome of EIB testing [104, 105]. Furthermore, the widespread use of inhaled steroids in the treatment of asthma reduces the response to exercise [106, 107]. In order to obtain the highest possible sensitivity level, the work-rate should be kept high. The 1999 ATS guidelines recommend that the work-rate should be $80-90 \%$ of the calculated maximum [90], and even higher levels, up to $95 \%$ of calculated maximum, may be advantageous [105].

In addition to diagnosing EIB, the reduction in FEV1 after standardised exercise may be considered as a measure of nonspecific bronchial hyperresponsiveness [108] and used to evaluate the severity of asthma, as well as the effects of therapy [107]. When an extra stimulus is added to the exercise test, by combining running on a treadmill with the inhalation of dry cold air at $-20^{\circ} \mathrm{C}$, the sensitivity of the test is markedly increased while simultaneously maintaining a high degree of specificity [109].

For other measures of indirect bronchial responsiveness, the sensitivity of exercise testing for EIB is rather low [110], especially in children treated with inhaled steroids [107]. This is understandable, as one of the main goals for treating asthma in childhood is the mastering of EIB. In children not treated with inhaled steroids, the sensitivity of the test is higher and 
comparable to that of methacholine or histamine bronchial provocation [111]. However, the specificity of the EIB test for the diagnosis of asthma is high $[109,110]$. By adding inhalation of cold air during the test, the sensitivity may be increased while maintaining the specificity [109]. Exercise load should be kept high to maintain the sensitivity [105].

\section{Interstitial lung disease}

ILD represents a broad and heterogeneous group of disorders, which display some common response patterns to exercise. As in other pulmonary conditions, exercise intolerance is multifactorial, but intolerable exertional symptoms, restrictive mechanics and severe gas-exchange derangements are often the primary contributors. Concomitant cardiovascular abnormalities and peripheral muscle dysfunction may also contribute [20]. Ventilatory response patterns typical of ILD have been well described: a reduced ventilatory capacity with reduced breathing reserve (albeit not as much as in COPD), an increased $V^{\prime} \mathrm{E}-V^{\prime} \mathrm{CO}_{2}$ slope, and a characteristically high breathing frequency and low $V \mathrm{~T}$ at any given level of $V^{\prime} \mathrm{E}$.

$V^{\prime} \mathrm{O}_{2}$,peak has been shown to be reproducible in ILD $[112,113]$ and is therefore a useful means to objectively measure exercise capacity, as is the case in COPD. Again, as for COPD, there are certain exercise response characteristics that are suggestive of ILD, although the diagnosis of ILD is rarely made with exercise testing. Pulmonary gas-exchange abnormalities during exercise may be the only physiological alteration evident in ILD [114, 115].

\section{Abnormalities in respiratory mechanics}

Exercise tolerance in patients with ILD is mostly limited by restrictive lung mechanics. Thus, there is a reduced ability to increase $V \mathrm{~T}$ and thence $V^{\prime} \mathrm{E}$ in response to the metabolic demands of exercise, consequent to a flattening of the lung compliance (volume-pressure) curve [116]. Also, the resting IC and inspiratory reserve volume (IRV) are frequently reduced. With exercise, end-expiratory lung volume (EELV) encroaches progressively onto the upper flatter regions of the alreadyflatter compliance curve, with further exacerbation of elastic load. Thus, VT "saturates" early and there is resultant tachypnoea with exaggerated tidal airflow excursions (see supplementary material, fig. 2, panel 7). A few small studies have indicated that IC remains largely unaltered throughout exercise in ILD, even in patients who exhibit expiratory flow limitation [117]. Avoidance of further encroachment of $V \mathrm{~T}$ on the expiratory reserve volume (ERV) would be expected to attenuate expiratory flow limitation over lower lung volumes. However, failure to decrease EELV during exercise (as occurs in healthy subjects) may have negative consequences with respect to work-sharing between the inspiratory and expiratory muscles.

Expiratory flow limitation has been described in some patients with ILD and may reflect airway obstruction as a result of smoking or airway involvement in the disease process [116, 117]. The lack of dynamic hyperinflation during exercise in these patients may reflect the already diminished IC at rest, such that patients may reach a critically reduced IRV and terminate exercise before air-trapping can occur.
Dyspnoeic intensity during exercise in ILD patients has been shown to correlate both with the increasing $V \mathrm{~T} / \mathrm{IC}$ ratio and with the increased inspiratory effort/displacement ratio (a crude index of respiratory neuromechanical dissociation) [118].

\section{Arterial oxygen desaturation}

As in COPD, arterial desaturation during exercise in ILD cannot be predicted on the basis of resting lung function. Most patients with moderate or severe pulmonary fibrosis show arterial desaturation during exercise [51, 52, 119]. Measuring the work-rate at which desaturation emerges may be of interest for patient counselling on demanding physical activities or for deciding the prescription of ambulatory oxygen therapy.

\section{Cardiac function}

Cardiovascular function is abnormal in many patients with ILD. During exercise, patients with ILD usually have elevated $f C$ with reduced stroke volume [120, 121], and an elevated pulmonary artery pressure is common in advanced ILD [122, 123]. Finally, clear cardiac involvement is evident in $\sim 5 \%$ of patients with sarcoidosis during exercise [124].

\section{Pulmonary vascular diseases}

In patients with chronic PVDs, such as $\mathrm{PPH}$, pulmonary hypertension associated with collagen-vascular diseases, chronic thromboembolic disease and pulmonary vasculitis, exercise tolerance is usually markedly reduced [22, 69, 125127]. This is mostly due to the increased pulmonary vascular resistance that prevents the normal increase in cardiac output during exercise [22]. Patients complain of intolerable dyspnoea on exertion, associated with an increased ventilatory response; typically this happens even during light physical activities and in the absence of abnormalities in resting pulmonary function. Resting DL,CO may be reduced, particularly in more severe disease, but not invariably in mild-to-moderate disease [128]. The typical pattern of exercise response consists of a reduced $V^{\prime} \mathrm{O}_{2}$,peak, $\theta \mathrm{L}$ and peak $\mathrm{O}_{2}$ pulse, a normal or slightly reduced breathing reserve, a high $V^{\prime} \mathrm{E} / V^{\prime} \mathrm{CO}_{2}$ (i.e. $>34$ at $\theta \mathrm{L}$ ) with a high $V \mathrm{D} / V \mathrm{~T}$ and an increased $P \mathrm{~A}-\mathrm{a}, \mathrm{O}_{2}[22,69,125]$. This pattern was shown to be $88 \%$ specific in distinguishing patients with pulmonary vascular resistances $>120$ dynes $\cdot \mathrm{sec} \cdot \mathrm{cm}^{-5}$ from those with lower values in a series of 130 patients referred because of unexplained exertion dyspnoea and fatigue [69].

In most cases, CPET can be performed safely in patients with $\mathrm{PPH}$ for functional and prognostic evaluation [22, 69, 125, 127]. However, exercise testing may not be indicated, or should be approached very cautiously, in patients with recent history of syncope or arrhythmias, and/or when signs of right-heart failure are present [129].

\section{Oxygen transport abnormalities}

During exercise, patients with PVD demonstrate significant $\mathrm{O}_{2}$ transport abnormalities: decreased $V^{\prime} \mathrm{O}_{2}$,peak and $V^{\prime} \mathrm{O}_{2}$-work-rate slope (see supplementary material, 1.2) and premature $\theta \mathrm{L}$. Recent research in patients with $\mathrm{PPH}$ has confirmed that reductions in $V^{\prime} \mathrm{O}_{2}$,peak not only reflect a reduced ability to deliver and utilise oxygen at the tissue level [22] but also that it is a reproducible measurement [130]. 


\section{Ventilatory and gas-exchange abnormalities}

Patients with PVD usually display a low $V^{\prime} E$ and a normal breathing reserve at peak exercise. In the majority of PVD patients, a significant feature is the increased $V^{\prime} \mathrm{E}$ at any given $V^{\prime} \mathrm{CO}_{2}$, relative to normal $[22,69,125]$. This reflects the increased physiological dead space consequent to reduced pulmonary perfusion, and is reflected in the widening of $\mathrm{PA}-\mathrm{a}, \mathrm{O}_{2}$ during exercise [22, 50, 69, 125]. A right-to-left shunt may also contribute to the arterial desaturation during exercise in a proportion of patients with coexistent patent foramen ovale [131]. Usually, $\mathrm{Pa}_{2} \mathrm{CO}_{2}$ is low at rest and does not fall further during exercise. This is thought to reflect hypoxaemic stimulation of carotid chemoreceptors and possibly also vagal reflex activation via stretch receptors in the pulmonary circulation [132].

The excessive $V^{\prime} \mathrm{E}$ at low absolute work-rates may also reflect the influence of a premature lactic acidaemia (i.e. $\theta \mathrm{L}$ is low, presumably because of cardiac impairment and/or coexistent deconditioning). The breathing pattern tends to be more rapid and shallow than normal. This pattern appears not to reflect restrictive lung mechanics, although little is known about respiratory mechanics during exercise in PVD. Animal studies suggest this tachypnoea may result from activation of vagally innervated mechanoreceptors in the right atrium, pulmonary vasculature and pulmonary interstitium [133].

\section{Chronic heart failure}

Exercise intolerance in CHF is complex and multifactorial [134] and, as for pulmonary disorders, resting indices of cardiac function (e.g. EF) fail to predict peak exercise capacity [135]. Cardiovascular factors are believed to be predominant in this regard and relate to impairment in the cardiac pump with an inability to increase cardiac output appropriately in response to the increased metabolic demands of exercise. However, abnormalities in locomotor muscle circulatory function have also been well described, including abnormal vasoregulatory control [136]. Consistent with this view is the demonstration from large population studies that leg discomfort is the most common exercise-limiting symptom in CHF [63].

\section{Cardiovascular abnormalities}

CPET has proved very useful in the detection and quantification of cardiovascular abnormalities during exercise in CHF. The characteristic findings are a reduced $V^{\prime} \mathrm{O}_{2}$, peak and $\theta \mathrm{L}$, a steeper $\mathrm{HR}-V^{\prime} \mathrm{O}_{2}$ relationship with a reduced $f C$ reserve at peak exercise and a shallower profile (or even flattening) of the $\mathrm{O}_{2}$ pulse increase with increasing $V^{\prime} \mathrm{O}_{2}$ (see supplementary material, 1.4 and fig. 4) [64, 137]. The following can also be observed: an increased $V^{\prime} \mathrm{E}-V^{\prime} \mathrm{CO}_{2}$ slope over the moderateintensity domain (i.e. up to $\theta \mathrm{L}$ ) [4, 138-140]; periodic breathing at rest and during the early phase of exercise; and expiratory airflow limitation at peak exercise. It should be noted that the previously mentioned alterations are not sufficiently specific for $\mathrm{CHF}$, however; they are observed, for instance, in patients with pulmonary vascular disorders $[22,69,125]$.

$V^{\prime} \mathrm{O}_{2}$,peak has been found to be reproducible in CHF patients [141, 142]. A normal $V^{\prime} \mathrm{O}_{2}$, peak virtually excludes CHF [21]. Exercise testing plays a minor role in the diagnosis of heart failure, but pulmonary gas-exchange data obtained during exercise provide important information on a patient's functional capacity and distinguish cardiovascular from pulmonary limitations during exercise [1, 2, 64-68].

As an objective measure of the patient's global aerobic capacity, $V^{\prime} \mathrm{O}_{2}$,peak offers advantages over other indices, such as the traditional New York Heart Association classification of functional impairment in CHF based upon a patient's symptoms rather than on objective criteria, in assessing the severity of CHF [143]. Because of the close relationship between $V^{\prime} \mathrm{O}_{2}$,peak and the maximal cardiac index, grading severity by $V^{\prime} \mathrm{O}_{2}$,peak provides an excellent measure of disease severity. The exercise capacity of patients with heart failure, based on $V^{\prime} \mathrm{O}_{2}$,peak and $\theta \mathrm{L}$, can be divided into four classes [13]. However, although widely used, this classification can be criticised because it fails to consider age, sex and weight differences. Despite this, stratification of ambulatory heart failure patients using Weber's classification has improved the ability to identify those with the poorest prognosis, and who should be considered for heart transplantation [144]. Guidelines for $V^{\prime} \mathrm{O}_{2}$,peak as a criterion for cardiac transplantation [144, 145] categorise patients for heart transplant according to $V^{\prime} \mathrm{O}_{2}$, peak (in $\mathrm{mL} \cdot \mathrm{kg}^{-1} \cdot \mathrm{min}^{-1}$ ) as follows. Accepted indication: $<10$; probable indication: $<14$; inadequate indication: $>15$.

\section{Ventilatory abnormalities}

In recent years, exaggerated ventilatory responses to exercise have repeatedly been reported in CHF patients [138-140]. $V^{\prime} \mathrm{O}_{2}$,peak is generally reduced, reflecting the reduced symptom-limited peak $V^{\prime} \mathrm{O}_{2}$, and the breathing reserve at peak exercise is normal or decreased. $V^{\prime} \mathrm{E}$ at any given $V^{\prime} \mathrm{CO}_{2}$ is typically increased. Contributory factors include: premature metabolic acidaemia (reflecting reduced $\mathrm{O}_{2}$ delivery and/or utilisation) [146, 147]; increased physiological dead space [4]; increased sympathetic system activation via mechano- or pressor-receptor stimulation in the exercising muscles [148152] and, possibly, contributions from cardiopulmonary vagal and sympathetic reflexes [132, 153, 154]. Several studies have shown that breathing pattern in $\mathrm{CHF}$ is more rapid and shallow than in healthy controls at any given $V^{\prime} E[4,155,156]$.

A few studies have measured respiratory mechanics during exercise in CHF $[157,158]$ Reduced static lung compliance has been described at rest, even in oedema-free patients [159]. Increased airways resistance and hyperresponsiveness have also been reported, even in nonsmokers, which may reflect mucosal oedema [160]. Recent data from the literature suggest that, despite breathing reserve usually being normal, CHF patients may develop expiratory airflow limitation at peak exercise and that this is the cause of exertional dyspnoea [158]. Patients who have resting expiratory flow limitation have been shown to demonstrate significant dynamic hyperinflation in exercise when ventilatory demands are increased [157]. The tachypnoeic breathing pattern responses may also reflect inspiratory muscle weakness, although the role of the latter in $\mathrm{CHF}$ remains conjectural. Dynamic hyperinflation during exercise in $\mathrm{CHF}$ would be expected to be associated with "high-end" mechanics, as in restrictive lung diseases.

Periodic fluctuations in $V^{\prime} \mathrm{O}_{2}$ and $V^{\prime} \mathrm{CO}_{2}$ at rest and at low workrates may be observed in patients with $\mathrm{CHF}$, particularly in the more severe cases [161-163]. The cause is unclear but might 
reflect periodic fluctuations in pulmonary perfusion and/or ventilation.

\section{Congenital heart diseases}

As early as 1982, American Heart Association guidelines were published for the use of exercise testing in children with cardiovascular diseases [164]. Subsequently, a treadmill protocol for children with congenital cardiac disorders, characterised by slow increases in both speed and inclination, has been developed [165]. FREDRIKSEN et al. [166] compared the level of fitness, as reflected by $\mathrm{V}^{\prime} \mathrm{O}_{2}$ peak, in 196 healthy children and 187 children with congenital heart diseases (CHD) and found that children with CHD had lower values that declined after the age of 12-13 yrs. MCMANUS and LEUNG [167] discussed how exercise testing could be optimised for diagnostic purposes in children with various heart diseases and recommended not only the measurement of $V^{\prime} \mathrm{O}_{2}$, but also that the assessment of $V^{\prime} \mathrm{O}_{2}$ and $V^{\prime} \mathrm{E}$ kinetics may help to discriminate between pulmonary, cardiovascular and deconditioning causes of exercise limitation. $V^{\prime} \mathrm{O}_{2}$,peak and the slope of the $V^{\prime} \mathrm{O}_{2}$-work-rate relationship have been used to evaluate improvements in exercise tolerance after heart surgery [168, 169]. The use of exercise testing in assessing the long-term prognosis of children with CHD has not been reported.

\section{UTILITY OF EXERCISE TESTING IN PROGNOSTIC EVALUATION}

CPET variables, as well as 6-MWD (table 1) have proven useful in the prognostic evaluation of patients with pulmonary and cardiac diseases (e.g. COPD, ILD, PPH, CF, CHF, candidacy for transplantation and for thoracic surgical procedures), and these are now a main indication for exercise testing in these patient groups. From the available literature, exercise tolerance $\left(V^{\prime} \mathrm{O}_{2}\right.$,peak, 6-MWD) and other CPET variables $\left(V^{\prime} \mathrm{E}-V^{\prime} \mathrm{CO}_{2}\right.$ slope, $\left.\theta \mathrm{L}, \mathrm{Sp}, \mathrm{O}_{2}\right)$ seem to be better predictors of prognosis than resting lung function and cardiac function.

Exercise tolerance is well recognised as a good predictor of mortality in healthy subjects, across ages ranging from young adults to elderly [170-173]. This also appears to be the case in a wide range of pulmonary and cardiovascular disease states. CHF currently provides the best instance of the establishment of a comprehensive cluster of CPET-based prognostic variables.

The purpose of this section is to consider prognostic value of CPET-related and other exercise tests in establishing the prognosis of patients with chronic respiratory and cardiac diseases. Data are available concerning the value of exercise indices in COPD, ILD, PVD, CF and CHF. Several other disease conditions for which CPET-based variables may provide good prognostic value fall outside the scope of the present discussion and are not discussed here.

\section{Chronic obstructive pulmonary disease}

Traditionally, FEV1 and age have been regarded as the most important predictors of mortality in COPD [174]. Other resting indices have been found to predict the prognosis of these patients, the most important being BMI [175, 176], IC/total lung capacity (TLC) ratio [177], arterial hypoxaemia during sleep [178], pulmonary artery pressure [179], mixed venous partial pressure of oxygen $\left(\mathrm{PO}_{2}\right)$ [180] and the degree of functional breathlessness [181].
In the past few years, COPD has come to be viewed as a systemic disorder in which many extrapulmonary aspects in addition to airflow limitation can influence survival. Skeletal muscle dysfunction is among these [182-184]. Therefore, there has been some focus on the prognostic value of correlates of exercise tolerance. The utility of CPET in evaluating disability and impairment in COPD patients has been established. However, the relationship between survival and CPET responses is not yet well established.

$\mathrm{V}^{\prime} \mathrm{O}_{2}$ peak

In COPD patients, OGA et al. [185] reported that $V^{\prime} \mathrm{O}_{2}$,peak is the most significant predictor of 5-yr mortality. In particular, $V^{\prime} \mathrm{O}_{2}$,peak $<654 \mathrm{~mL} \cdot \mathrm{min}^{-1}$ was associated with $60 \%$ mortality at 5 yrs and $V^{\prime} \mathrm{O}_{2}$,peak $793-995 \mathrm{~mL} \cdot \mathrm{min}^{-1}$ was associated with $5 \%$ mortality at 5 yrs (fig. 2).

Recently, HiRAGA et al. [186] conducted a large retrospective study focused on the prognostic value of many CPET variables, including directly measured $\mathrm{Pa}_{2} \mathrm{O}_{2}$. They confirmed the prognostic value of $V^{\prime} \mathrm{O}_{2}$, peak, reporting a 5-yr mortality of $62 \%$ for $V^{\prime} \mathrm{O}_{2}$,peak $<10 \mathrm{~mL} \cdot \mathrm{min}^{-1} \cdot \mathrm{kg}^{-1}$. However, the severity of exercise-induced hypoxaemia evaluated by the slope of the $P a, \mathrm{O}_{2}-V^{\prime} \mathrm{O}_{2}$ relationship $\left(\Delta \mathrm{Pa}_{1} \mathrm{O}_{2} / \Delta V^{\prime} \mathrm{O}_{2}\right.$ or " $\mathrm{Pa}, \mathrm{O}_{2}$ slope" $)$ was the independent prognostic factor most closely associated with the survival time. In particular, a $\mathrm{Pa}_{\mathrm{a}_{2}} \mathrm{O}_{2}$ slope $<-80 \mathrm{mmHg} \cdot \mathrm{L}^{-1}$. $\mathrm{min}^{-1}$ was associated with an elevated mortality risk, with $<20 \%$ survival at 5 yrs.

\section{Timed walking tests}

The earliest data regarding the ability of field tests to predict mortality refer to post-rehabilitation outcomes of patients with advanced pulmonary disease. GERARDI et al. [187] concluded that the post-rehabilitation 12-min walking test distance was the strongest predictor of survival up to 3 yrs post-intervention in individuals with predominantly moderate-to-severe COPD, independent of the cause of death. This observation was later confirmed by BOWEN et al. [188], using the 6-MWT. A recent study [189] focused on the decline of 6-MWD over 2 yrs in COPD patients; the authors of that study found that the magnitude of change in the group that survived was significantly lower than in nonsurvivors. Very recently, the 6MWT distance was integrated in a grading system called BODE (Body mass index, airflow Obstruction, Dyspnoea, Exercise capacity), formulated to categorise and predict outcome in patients with COPD. In a cohort of 625 patients, CELLI et al. [190] have prospectively validated the BODE index as a good predictor of death from any cause and from respiratory causes after correction for coexisting conditions. The authors reported that the index was a significantly better predictor of mortality than FEV1 alone.

The pre-operative value of exercise tests as an outcome measure in lung-volume reduction surgery (LVRS) has been explored. SZEKELY et al. [191] reported that a 6-MWD $<200 \mathrm{~m}$ before or after pulmonary rehabilitation is an excellent preoperative predictor of unacceptable post-operative mortality at 6 months, with a specificity of $84 \%$. Similarly, a randomised controlled study by GEDDES et al. [192], to evaluate the effect of LVRS in patients with emphysema, indicated that a preoperative shuttle walk test (SWT) distance $<150 \mathrm{~m}$ was a predictor of high peri-operative mortality. Interestingly, in the 


\begin{tabular}{|c|c|c|c|c|c|c|}
\hline \multirow[t]{2}{*}{ TABLE 1} & \multicolumn{6}{|c|}{$\begin{array}{l}\text { Exercise indices that have been shown to predict } \\
\text { the prognosis of patients with chronic respiratory } \\
\text { and cardiac diseases }\end{array}$} \\
\hline & & COPD & ILD & PVD & CF & CHF \\
\hline \multicolumn{2}{|l|}{$\begin{array}{l}V^{\prime} \mathrm{O}_{2, \text { peak }} \\
\theta \mathrm{L}\end{array}$} & + & + & + & + & $\begin{array}{l}+ \\
+\end{array}$ \\
\hline \multicolumn{2}{|c|}{$\begin{array}{l}V^{\prime} \mathrm{E}-V^{\prime} \mathrm{CO}_{2} \text { slope and } \\
V^{\prime} \mathrm{E}-V^{\prime} \mathrm{CO}_{2} \text { at } \theta \mathrm{L}\end{array}$} & & + & & & + \\
\hline \multicolumn{2}{|c|}{ Arterial desaturation } & & + & + & + & \\
\hline \multicolumn{2}{|c|}{ 6-MWD } & + & & + & & + \\
\hline \multicolumn{7}{|c|}{$\begin{array}{l}\text { COPD: chronic obstructive pulmonary disease; ILD: interstitial lung disease; } \\
\text { PVD: pulmonary vascular disorders; CF: cystic fibrosis; } \mathrm{CHF} \text { : chronic heart } \\
\text { failure; } V^{\prime} \mathrm{O}_{2} \text {,peak: peak oxygen uptake; } \theta \mathrm{L} \text { : lactate threshold; } V^{\prime} E-V^{\prime} \mathrm{CO}_{2} \text { : } \\
\text { ventilatory equivalent for carbon dioxide; } 6-\mathrm{MWD}: 6 \text {-min walking test distance. } \\
\text { +: sensitive; ++: more sensitive. }\end{array}$} \\
\hline
\end{tabular}

National Emphysema Treatment Trial [193], exercise capacity was used to identify the subgroup of patients for whom LVRS has the most favourable survival and cost-effectiveness compared with medical therapy. This important trial reported that patients with a pre-operative peak work-rate $<25 \mathrm{~W}$ for females and $<40 \mathrm{~W}$ for males who also had predominantly upper-lobe emphysema manifest significant improvements in survival and functional outcomes at $3 \mathrm{yrs}$, compared with medical treatment.

Risks of peri-operative complications are often stratified by $V^{\prime} \mathrm{O}_{2}$,peak. A value below a threshold of $15 \mathrm{~mL} \cdot \mathrm{min}^{-1} \cdot \mathrm{kg}^{-1}$ indicates a significant risk of complications. Data on field exercise tests are limited, however. For patients with COPD, a 6-MWD of $250 \mathrm{~m}$ would correspond approximately to this threshold. KADIKAR et al. [194] retrospectively observed the sensitivity and specificity of the 6-MWT to predict death in 145 patients who had undergone lung transplantation; a distance $<400 \mathrm{~m}$ appeared be an appropriate marker for listing patients for transplant. For LVRS, the threshold for a successful outcome has been reported to be $\sim 150 \mathrm{~m}$ for the SWT [192] or $200 \mathrm{~m}$ for the 6-MWT [191].

\section{Interstitial lung diseases}

In patients with ILD, CPET may be particularly useful in detecting exercise-related ventilatory and gas-exchange abnormalities (e.g. arterial desaturation and an elevated ventilatory requirement) early in the course of the disease when resting lung-function measurements appear to be normal. Perhaps more importantly, arterial desaturation and other CPET indices have proven useful in predicting the prognosis of patients with ILD.

\section{Arterial oxygen desaturation}

A large study conducted by KING et al. [195] focused on developing a clinical-radiological-physiological (CPR) scoring system that predicts survival in patients with ILD with biopsyproven usual interstitial pneumonia (UIP). $\mathrm{Pa}_{1} \mathrm{O}_{2}$ at peak exercise was found to be a significant independent predictor of survival, accounting for as much as $10.5 \%$ of the maximum CPR score in the completed model. LAMA et al. [52] reported

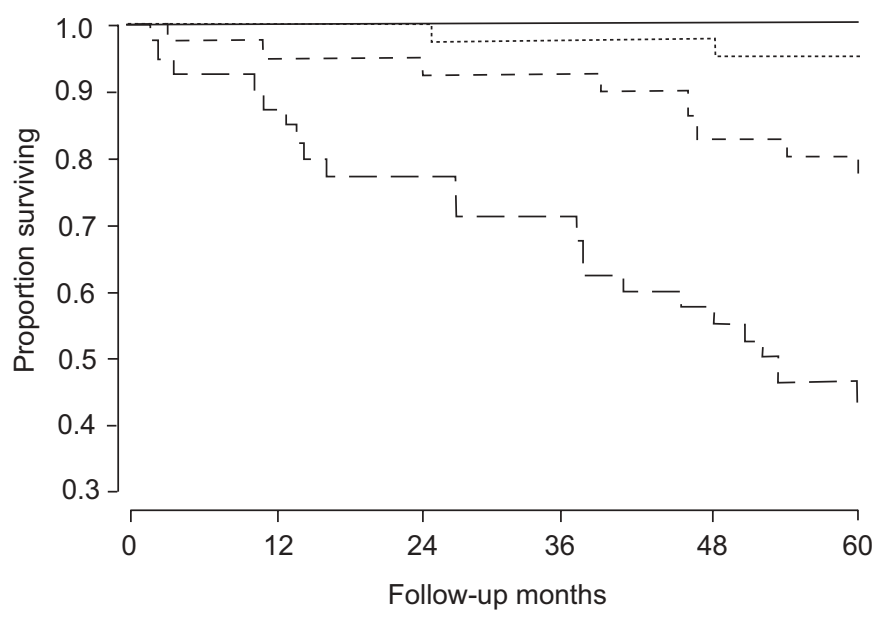

FIGURE 2. Kaplan-Meier survival curves using quartiles of peak oxygen uptake $\left(V^{\prime} \mathrm{O}_{2}\right.$, peak). ——: $V^{\prime} \mathrm{O}_{2}$, peak $>995 \mathrm{~mL} \cdot \mathrm{min}^{-1}(\mathrm{n}=37) ; \cdots \cdots \cdots: V^{\prime} \mathrm{O}_{2}$, peak 793 $995 \mathrm{~mL} \cdot \mathrm{min}^{-1}(\mathrm{n}=38)$; -----: $V^{\prime} \mathrm{O}_{2}$,peak $654-792 \mathrm{~mL} \cdot \mathrm{min}^{-1}(\mathrm{n}=38)$; - - -: V'O $\mathrm{O}_{2}$, peak: $<654 \mathrm{~mL} \cdot \mathrm{min}^{-1}(\mathrm{n}=37)$. Reproduced from [185] with permission from the publisher.

that exercise-induced desaturation $<88 \%$ during the 6-MWT was strongly predictive of mortality in patients with ILD and biopsy-proven UIP.

$V^{\prime} \mathrm{O}_{2}$, peak and $V^{\prime} \mathrm{E} / \mathrm{V}^{\prime} \mathrm{CO}_{2}$

A retrospective study of 41 patients with a clinical diagnosis of idiopathic pulmonary fibrosis reported that $\mathrm{Pa}_{\mathrm{a}_{2}}$ slope, $V^{\prime} \mathrm{O}_{2}$,peak, $\mathrm{O}_{2}$ pulse at peak exercise and $V^{\prime} \mathrm{E} / V^{\prime} \mathrm{CO}_{2}$ at peak exercise are significant predictors of survival [196]. Interestingly, among the above indices, $\mathrm{Pa}, \mathrm{O}_{2}$ slope was correlated most closely with the survival rate.

The present authors know of no studies regarding the prognostic value of pre-operative exercise indices in relation to survival after lung transplantation in ILD patients.

\section{Primary pulmonary hypertension}

$\mathrm{PPH}$ is a relatively rare condition associated with high mortality. In recent years, new drugs have been used (e.g. prostacycline, bosentan), aimed at reducing the degree of pulmonary hypertension, although lung transplant remains the only definitive cure. In the past, invasive techniques (i.e. right-heart catheterisation with measurement of pulmonary artery pressure and cardiac output) have been used to assess the severity of $\mathrm{PPH}$, the response to interventions and the timing of transplant. More recently, exercise testing (often considered unacceptably hazardous in the past) has been used to define disease severity and prognosis.

$\mathrm{V}^{\prime} \mathrm{O}_{2}$, peak

WENSEL et al. [127] studied the prognostic value of $V^{\prime} \mathrm{O}_{2}$,peak in patients with $\mathrm{PPH}$. They reported that $\mathrm{PPH}$ patients with $V^{\prime} \mathrm{O}_{2}$,peak $\leqslant 10.4 \mathrm{~mL} \cdot \mathrm{min}^{-1} \cdot \mathrm{kg}^{-1}$ have a $50 \%$ risk of early death at $1 \mathrm{yr}$ and $85 \%$ at $2 \mathrm{yrs}$, whereas patients with $V^{\prime} \mathrm{O}_{2}$,peak $>10.4 \mathrm{~mL} \cdot \mathrm{min}^{-1} \cdot \mathrm{kg}^{-1}$ have a $10 \%$ risk of early death at $1 \mathrm{yr}$ and $30 \%$ at 2 yrs. In addition, they reported that patients who had both $V^{\prime} \mathrm{O}_{2}$,peak $\leqslant 10.4 \mathrm{~mL} \cdot \mathrm{min}^{-1} \cdot \mathrm{kg}^{-1}$ and peak systolic blood pressure $<120 \mathrm{mmHg}$ had a very poor survival rate at 12 months $(23 \%)$, whereas patients with one or none of these risk factors had better survival rates (79\% and $97 \%$, respectively; fig. 3). 


\section{6-MWD and arterial desaturation}

In $\mathrm{PPH}$ patients, 6-MWT performance correlates well with $V^{\prime} \mathrm{O}_{2}$,peak. Again, there appears to be some prognostic value for the 6-MWT. Patients walking $<332 \mathrm{~m}$ had a significantly lower survival rate than those walking further. In particular, in the short-distance group the survival rate at 20 months was $20 \%$, compared with the long-distance group in which there was a $90 \%$ survival rate [197]. Exercise-induced hypoxaemia as measured by pulse oximetry during the 6-MWT was observed to be significantly predictive of mortality in patients with $\mathrm{PPH}$ [198].

\section{Cystic fibrosis}

Many variables have been examined and some have proven to have a good predictive value for prognosis in CF patients. Indices of pulmonary function at rest, in particular FEV1 (as \% pred or as the magnitude of its deterioration over time) have been shown to be good predictors of mortality. FEV1 along with $\mathrm{Pa}, \mathrm{O}_{2}, \mathrm{~Pa}_{2} \mathrm{CO}_{2}$, age and sex are the major indices used to classify the severity of $\mathrm{CF}$ and for referral for lung transplantation [199-202].

There are, however, differences in clinical outcome among CF patients with similar resting functional indices. Other factors have therefore been explored, such as malnutrition (e.g. low BMI) and recurrent infections of the respiratory tract with polyresistant pathogens (e.g. Pseudomonas spp., Burkholderia серасіа) [203-206].

Physical activity is regarded as particularly important in children with CF and assessment of physical fitness as an important measure of prognosis. The degree of fitness will (in addition to the level of physical activity) depend upon the progression of the pulmonary part of the disorder [207-209].

\section{$\mathrm{V}^{\prime} \mathrm{O}_{2}$ peak and ventilatory indices}

Many studies have confirmed that the value of $V^{\prime} \mathrm{O}_{2}$,peak is equal or superior to that of resting tests in the stratification and prognostic evaluation of patients with CF. NiXON et al. [203] followed 109 CF patients, age of 7-35 yrs, for 8 yrs after initial

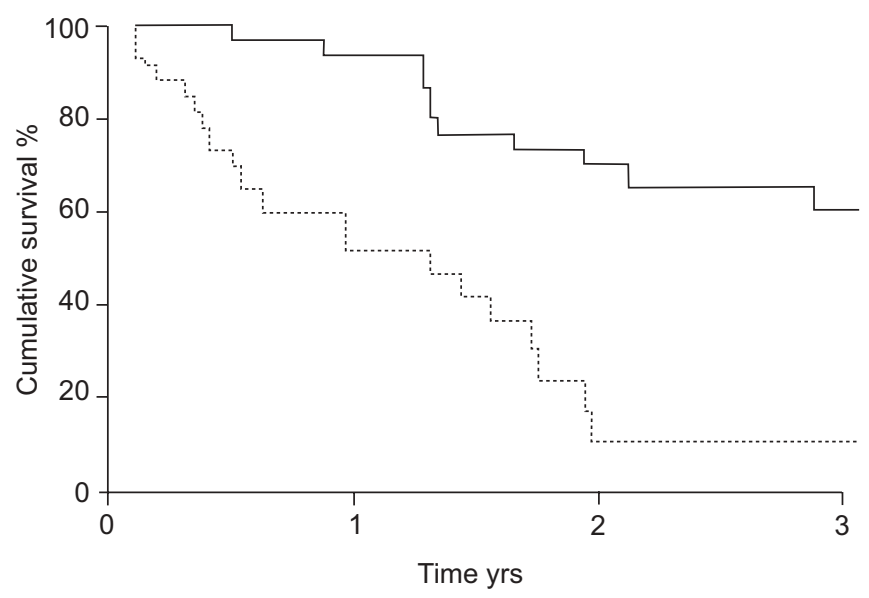

FIGURE 3. Kaplan-Meier cumulative survival curves for 3-yr survival of 70 patients with primary pulmonary hypertension. Patients with a peak oxygen uptake $\left(V^{\prime} \mathrm{O}_{2}\right.$, peak $)>10.4 \mathrm{~mL} \cdot \mathrm{kg}^{-1} \cdot \mathrm{min}^{-1}\left({ }^{-}\right)$versus $\leqslant 10.4 \mathrm{~mL} \cdot \mathrm{kg}^{-1} \cdot \mathrm{min}^{-1}(\cdots \cdots \cdots)$. Reproduced from [127] with permission from the publisher. exercise testing and calculated survival rates. Patients with the highest levels of aerobic fitness $\left(V^{\prime} \mathrm{O}_{2}\right.$,peak $\geqslant 82 \%$ pred) had a survival rate of $83 \%$, compared to $51 \%$ and $28 \%$ for patients with middle $\left(V^{\prime} \mathrm{O}_{2}\right.$,peak, $\left.59-81 \%\right)$ and lowest $\left(V^{\prime} \mathrm{O}_{2}\right.$,peak $\leqslant 58 \%$ pred) fitness levels, respectively. After adjustment for other risk factors, patients with higher aerobic fitness levels were more than three times as likely to survive as patients with lower fitness levels. STANGHELLE et al. [210] showed comparable findings in their 8-yr follow up of 8-16-yr-old CF boys. MoORCROFT et al. [211] have found that $V^{\prime} \mathrm{O}_{2}$,peak, peak workrate, $V^{\prime}$ E,peak and $V^{\prime} \mathrm{E} / V^{\prime} \mathrm{CO}_{2}$ at peak exercise are all significant predictors of mortality. In contrast to previous studies, however, they found FEV1 to be a better predictor than exercise measures.

\section{Arterial desaturation and walking distance}

BALFOUR-LYNN et al. [212] compared a 3-min step test with a 6MWT and found both useful in the assessment of exercise tolerance in children with CF, whereas SELVADURAI et al. [213] and POUESSEL et al. [214] validated a shuttle test in CF children and found this a useful test.

In field test studies, the indices most commonly used for patient evaluation are the distance walked, the lowest $S \mathrm{p}, \mathrm{O}_{2}$ and $f_{C}$ [215]. Some authors have found that $V^{\prime} \mathrm{O}_{2}$,peak in patients with CF was correlated with 6-MWD, with the correlation coefficient increasing if age, weight, FVC, FEV1 and DL,CO were added to the prediction equation [216, 217]. However, other authors have found no correlation between distance covered in a 12-MWT and survival [202]. Other authors reported that an elevated breathing reserve at $\theta \mathrm{L}$ (defined as $V^{\prime} \mathrm{E}$ at $\theta \mathrm{L}$ divided by the MVV) is associated with an increased risk of death in CF patients awaiting lung transplantation [218]. The utility of this breathing reserve index rests on the fact that it combines a resting measure of lung function with a measure of exercise capacity that does not depend on patients attaining the point of symptom limitation.

\section{Chronic heart failure}

Exercise testing in cardiac patients has been used extensively to confirm the clinical suspicion of coronary ischaemia and, perhaps more importantly, to establish prognoses [219, 220]. Guidelines for the indications and interpretation of exercise testing in patients with coronary artery disease are available [68].

More recently, CPET has been increasingly used to assess the degree and mechanism of exercise intolerance in patients with heart disease. $V^{\prime} \mathrm{O}_{2}$, peak, $\theta \mathrm{L}, V^{\prime} \mathrm{E} / V^{\prime} \mathrm{CO}_{2}$ and other physiological variables have been used as measures of functional status in patients with CHF. Perhaps more importantly, several studies have been published on the usefulness of CPET measurements in the prognostic evaluation of CHF patients. What is not entirely clear, however, is how $\beta$-adrenergic blockade therapy, through effects on indices such as $V^{\prime} \mathrm{O}_{2}$,peak and $V^{\prime} \mathrm{E}-V^{\prime} \mathrm{CO}_{2}$ slope, may alter prognostic prediction in CHF. However, PETERSON et al. [221] and O'NeILl et al. [222] have recently reported the prognostic value of peak $V^{\prime} \mathrm{O}_{2}$ to be unaffected with $\beta$-blockade in $\mathrm{CHF}$, although the latter authors have suggested that the $14 \mathrm{~mL} \cdot \mathrm{kg}^{-1} \cdot \mathrm{min}^{-1}$ cut-off for cardiac transplantation may require re-evaluation in this setting. 
$V^{\prime} \mathrm{O}_{2}$, peak

$V^{\prime} \mathrm{O}_{2}$,peak has consistently demonstrated prognostic significance in $\mathrm{CHF}[223,224]$, with lower $V^{\prime} \mathrm{O}_{2}$,peak predicting higher mortality and the need for heart transplant. MANCINI et al. [225] reported that $V^{\prime} \mathrm{O}_{2}$,peak $>14 \mathrm{~mL} \cdot \mathrm{min}^{-1} \cdot \mathrm{kg}^{-1}$ is associated with $94 \%$ survival at $1 \mathrm{yr}$ and $84 \%$ survival at $2 \mathrm{yrs}$; while patients with $V^{\prime} \mathrm{O}_{2}$,peak $\leqslant 14 \mathrm{~mL} \cdot \mathrm{min}^{-1} \cdot \mathrm{kg}^{-1}$, who were rejected for transplant for noncardiac reasons, had survival rates at 1 and 2 yrs of $47 \%$ and $32 \%$, respectively. KLEBER et al. [226] reported a better prognosis at 30 months for patients with $V^{\prime} \mathrm{O}_{2}$,peak $>45 \%$ pred. SZLACHCIC et al. [227] reported that $V^{\prime} \mathrm{O}_{2}$,peak $<10 \mathrm{~mL} \cdot \mathrm{min}^{-1} \cdot \mathrm{kg}^{-1}$ is associated with $77 \%$ mortality at $1 \mathrm{yr}$, while in patients with $V^{\prime} \mathrm{O}_{2}$, peak $>10 \mathrm{~mL} \cdot \mathrm{min}^{-1} \cdot \mathrm{kg}^{-1}$ mortality rate at $1 \mathrm{yr}$ is $\sim 20 \%$. More recently, GITT et al. [138] reported that CHF patients with $V^{\prime} \mathrm{O}_{2}$,peak $\leqslant 14 \mathrm{~mL} \cdot \mathrm{min}^{-1} \cdot \mathrm{kg}^{-1}$ (or $\leqslant 50 \%$ pred) had a three-fold increased risk of death at 6 months [138]. ARENA et al. [228] confirmed that $V^{\prime} \mathrm{O}_{2}$,peak $<14 \mathrm{~mL} \cdot \mathrm{min}^{-}$ ${ }^{1} \cdot \mathrm{kg}^{-1}$ conveyed a poor prognosis (sensitivity $84 \%$; specificity $48 \%$ ). In some of the previously-mentioned studies [138, 227, 228], it was observed that the combination of CPET variables, particularly $V^{\prime} \mathrm{O}_{2}$,peak and $V^{\prime} \mathrm{E}-V^{\prime} \mathrm{CO}_{2}$ slope, better identifies patients at high risk of early death from $\mathrm{CHF}$ than $V^{\prime} \mathrm{O}_{2}$,peak alone (see below).

There is now a general consensus that patients with $V^{\prime} \mathrm{O}_{2}$,peak $<14 \mathrm{~mL} \cdot \mathrm{min}^{-1} \cdot \mathrm{kg}^{-1}$ should be considered for heart transplantation, as originally stated in the report of the 24th Bethesda Conference [145].

\section{Lactate threshold}

Because of the poor cardiovascular adaptation, the development of lactic acidaemia in patients with $\mathrm{CHF}$ occurs prematurely early in the course of an incremental exercise test. Some authors prefer to use $\theta \mathrm{L}$ values, rather than $V^{\prime} \mathrm{O}_{2}$,peak, to assess patients' functional status instead of $V^{\prime} \mathrm{O}_{2}$,peak because (in contrast to $\theta \mathrm{L}$ ) the latter is highly effortdependent. However, only one study has examined the prognostic value of $\theta \mathrm{L}$ in $\mathrm{CHF}$ patients: GITT et al. [138] demonstrated that $\theta \mathrm{L}<11 \mathrm{~mL} \cdot \mathrm{min}^{-1} \cdot \mathrm{kg}^{-1}$ is associated with a mortality risk ratio at 6 months of 2.7 (similar to the risk ratio of 2.9 for $V^{\prime} \mathrm{O}_{2}$, peak $\leqslant 14 \mathrm{~mL} \cdot \mathrm{min}^{-1} \cdot \mathrm{kg}^{-1}$ ).

$V^{\prime} \mathrm{E} / \mathrm{V}^{\prime} \mathrm{CO}_{2}$ at $\theta \mathrm{L}$ and $V^{\prime} \mathrm{E}-V^{\prime} \mathrm{CO}_{2}$ slope

Evidence has been provided about the utility of $V^{\prime} \mathrm{E} / V^{\prime} \mathrm{CO}_{2}$ measurements in patients with CHF. Unless there is a concomitant lung disease that worsens the alveolar ventilation/perfusion ratio, an increase in $V^{\prime} \mathrm{E} / V^{\prime} \mathrm{CO}_{2}$ usually reflects an impairment in lung gas diffusion and/or the development of pulmonary hypertension during exercise. As emphasised earlier, $\mathrm{Pa}, \mathrm{CO}_{2}$ should be measured to rule out the possibility that an increased $V^{\prime} \mathrm{E} / V^{\prime} \mathrm{CO}_{2}$ and /or $V^{\prime} \mathrm{E}-V^{\prime} \mathrm{CO}_{2}$ slope reflects hyperventilation.

There has been recent interest in using the $V^{\prime} \mathrm{E}-V^{\prime} \mathrm{CO}_{2}$ slope, in addition to $V^{\prime} \mathrm{O}_{2}$,peak, to assess the prognosis of patients with CHF [138-140, 227, 229-232]. As described in the supplementary material (section 1.5), normal values for the $V^{\prime} \mathrm{E}-V^{\prime} \mathrm{CO}_{2}$ slope are in the region of 23-25 (i.e. below the respiratory condensation point). A $V^{\prime} \mathrm{E}-V^{\prime} \mathrm{CO}_{2}$ slope $>130 \%$ pred is associated with a 1-yr mortality rate $>40 \%$ [226]. In a study of 470 patients, an abnormal elevation in the peak $V^{\prime} \mathrm{E} / V^{\prime} \mathrm{CO}_{2}$ $\geqslant 44.7$ was the strongest predictor of death during a $1.5-\mathrm{yr}$ follow-up [232]. A $V^{\prime} \mathrm{E}-V^{\prime} \mathrm{CO}_{2}$ slope $>34$ has been shown to be a better predictive index for early death (6 months) from $\mathrm{CHF}$ than $V^{\prime} \mathrm{O}_{2}$,peak [138]. An elevated ventilatory response to exercise can reflect decreased ventilatory efficiency (increased $V \mathrm{D} / V \mathrm{~T})$, and is predictive of outcome in patients with preserved exercise capacity. In another study of 123 patients with a $V^{\prime} \mathrm{O}_{2}$,peak $\geqslant 18 \mathrm{~mL} \cdot \mathrm{min}^{-1} \cdot \mathrm{kg}^{-1}$, the 3 -yr survival was significantly lower in those with a peak $V^{\prime} \mathrm{E} / V^{\prime} \mathrm{CO}_{2} \geqslant 34\left(57 \%\right.$ versus $93 \%$ for $V^{\prime} \mathrm{E} / V^{\prime} \mathrm{CO}_{2}$ \$34) [140]. A $V^{\prime} \mathrm{E}-V^{\prime} \mathrm{CO}_{2}$ slope $>34$ is a significantly better predictor of both 1-yr cardiac-related mortality and 1-yr cardiacrelated hospitalisation than $V^{\prime} \mathrm{O}_{2}$,peak [228].

\section{Walking tests}

The utility of the 6-MWT has been examined in mild-tomoderate [233] and more severe [234] CHF patients. Both studies associated a distance $<300 \mathrm{~m}$ with a reduced mediumto-long-term overall survival and reduced event-free survival. In more severe $\mathrm{CHF}$ patients, baseline 6-MWT distance was a strong independent predictor of mortality and hospitalisation at $1 \mathrm{yr}$ [235]. The feasibility of the SWT for selection for heart transplantation has been documented; a distance of $>450$ m equates to a $V^{\prime} \mathrm{O}_{2}$, peak for treadmill walking $>14 \mathrm{~mL} \cdot \mathrm{min}^{-1} \cdot \mathrm{kg}^{-1}[236]$.

\section{Combinations of variables}

GITT et al. [138] examined the prognostic value of CPET variables, alone or in combination in a large cohort of $\mathrm{CHF}$ patients. They reported that $\theta \mathrm{L}<11 \mathrm{~mL} \cdot \mathrm{min}^{-1} \cdot \mathrm{kg}^{-1}$ and $V^{\prime} \mathrm{E}-$ $V^{\prime} \mathrm{CO}_{2}$ slope $>34$ combined better identified patients at high risk for early death than $V^{\prime} \mathrm{O}_{2}$,peak $\left(\leqslant 14 \mathrm{~mL} \cdot \mathrm{min}^{-1} \cdot \mathrm{kg}^{-1}\right.$ or $\leqslant 50 \%$ pred $)$ alone or in combination with $\theta \mathrm{L}\left(<11 \mathrm{~mL} \cdot \mathrm{min}^{-1}\right.$. $\mathrm{kg}^{-1}$ ) or with $V^{\prime} \mathrm{E}-V^{\prime} \mathrm{CO}_{2}$ slope $(>34)$.

In studies that used multivariate Cox regression analysis, $V^{\prime} \mathrm{E}-$ $V^{\prime} \mathrm{CO}_{2}$ slope appears to be the most powerful predictor of eventfree survival, followed by $V^{\prime} \mathrm{O}_{2}$,peak (table 2) [138, 226, 228].

\section{UTILITY OF EXERCISE TESTING IN DEFINING RESPONSES TO INTERVENTIONS}

CPET variables as well as distance covered during walking tests have proven to be useful in clinical trials evaluating interventions in patients with pulmonary and cardiac diseases (e.g. COPD, ILD, CF, PPH, CHF). This is now the main indication for exercise testing in these patient groups. CPET variables, as well as distance covered during walking tests, have proven to be useful in individual prescription of pulmonary rehabilitation and $\mathrm{O}_{2}$ supplementation (by exercise testing pre- and post-intervention), and also for prescription of exercise training. These are now main indications for exercise testing in these patient groups. Indeed, the use of an initial CPET-based assessment prior to entering an exercise training programme is to be strongly recommended.

Exercise tolerance has become an important outcome measure in patients with COPD, CHF and other chronic diseases, mostly because evidence has been provided that exercise testing is superior to other functional measurements obtained at rest (e.g. FEV1, left ventricular EF) in demonstrating the positive effect of a specific intervention. In particular, exercise testing has been widely used in cardiorespiratory disease to explore the short- and long-term benefits of exercise-based rehabilitation, nutritional or hormonal therapy, drug therapy, 


\begin{tabular}{|c|c|c|c|c|}
\hline TABLE 2 & \multicolumn{4}{|c|}{$\begin{array}{l}\text { Cox regression analysis, including sex, age, left } \\
\text { ventricular ejection fraction, and New York Heart } \\
\text { Association class, for calculation of risk of death } \\
\text { at } 6 \text { months }\end{array}$} \\
\hline \multicolumn{2}{|c|}{ Cardiopulmonary variable } & Risk ratio & $95 \% \mathrm{Cl}$ & p-value \\
\hline \multicolumn{2}{|c|}{$V^{\prime} \mathrm{O}_{2}$, peak $\leqslant 14 \mathrm{~mL} \cdot \mathrm{kg}^{-1} \cdot \mathrm{min}^{-1}$} & 2.9 & $1.5-5.4$ & 0.002 \\
\hline \multicolumn{2}{|c|}{$V^{\prime} \mathrm{O}_{2}$, peak $\leqslant 10 \mathrm{~mL} \cdot \mathrm{kg}^{-1} \cdot \mathrm{min}^{-1}$} & 2.1 & $1.1-4.3$ & 0.04 \\
\hline \multicolumn{2}{|c|}{$V^{\prime} \mathrm{O}_{2, \text { peak }} \leqslant \mathbf{5 0 \%}$ normal } & 2.0 & $1.1-3.7$ & 0.03 \\
\hline \multicolumn{2}{|c|}{$\theta \mathrm{L}<11 \mathrm{~mL} \cdot \mathrm{kg}^{-1} \cdot \mathrm{min}^{-1}$} & 2.7 & $1.3-5.6$ & 0.007 \\
\hline \multicolumn{2}{|c|}{$V^{\prime} E-V^{\prime} \mathrm{CO}_{2}$ slope $>34$} & 2.7 & $1.5-5.1$ & 0.001 \\
\hline \multicolumn{2}{|c|}{$V^{\prime} \mathrm{O}_{2}$, peak $\leqslant 14+\theta \mathrm{L}<11 \mathrm{~mL} \cdot \mathrm{kg}^{-1} \cdot \mathrm{min}^{-1}$} & 3.2 & $1.5-6.7$ & 0.003 \\
\hline \multicolumn{2}{|c|}{$\begin{array}{l}V^{\prime} \mathrm{O}_{2} \text {,peak } \leqslant 14 \mathrm{~mL} \cdot \mathrm{kg}^{-1} \cdot \mathrm{min}^{-1}+V^{\prime} \mathrm{E}-V^{\prime} \mathrm{CO}_{2} \\
\text { slope }>34\end{array}$} & 4.5 & 2.1-10 & $<0.001$ \\
\hline \multicolumn{2}{|c|}{$\begin{array}{l}\theta \mathrm{L}<11 \mathrm{~mL} \cdot \mathrm{kg}^{-1} \cdot \mathrm{min}^{-1}+V^{\prime} \mathrm{E}-V^{\prime} \mathrm{CO}_{2} \\
\quad \text { slope }>\mathbf{3 4}\end{array}$} & 5.1 & $2.0-12.7$ & 0.001 \\
\hline
\end{tabular}

$\mathrm{Cl}$ : confidence interval $\mathrm{V}^{\prime} \mathrm{O}_{2}$,peak: peak oxygen uptake; $\theta \mathrm{L}$ : lactate threshold; $V^{\prime} \mathrm{E}-V^{\prime} \mathrm{CO}_{2}$ slope: slope of the increase in ventilatory equivalent for carbon dioxide. Reprinted from [138] with permission from the publisher.

$\mathrm{O}_{2}$ or heliox breathing, and surgical interventions such as LVRS and transplantation.

\section{What is the "best" measure of improvement in exercise tolerance?}

Laboratory-based tests allow evaluation of therapeutic effects mostly by detecting improvement of exercise capacity as well as characterising ventilatory, gas-exchange, circulatory and metabolic response patterns, but are limited by the setting and by expensive equipment. Walking tests can be used easily in a field setting and are inexpensive, but they provide less information regarding the specific physiological responses underlying altered exercise capacity.

Different exercise protocols and different exercise measures have been used to quantify the improvement of exercise tolerance in patients with cardiorespiratory diseases, although the laboratory symptom-limited incremental test, with measurement of $V^{\prime} \mathrm{O}_{2}$,peak or peak work-rate, and walking tests, with measurement of maximal distance walked, have been most popular. More recently, indices reflecting the patient's endurance capacity have succesfully been used. The most common and popular of these is the time to symptom limitation on a constant-load cycle-ergometer test, although a few studies have actually defined the power-duration relationship and estimated critical power (CP; see supplementary material, 2.2 and fig. 8).

Comparisons between incremental and endurance cycleergometry tests indicate that the incremental exercise test is excellent at describing the profile of system abnormality but less suitable than endurance cycle-ergometry for discriminating the outcome of interventions in terms of improved exercise capacity. A necessary prerequisite for employing constant-load exercise testing as an outcome measure in pulmonary rehabilitation, and also in drugs studies, is individualising the work-rate to be performed in the pre-rehabilitation study. Power-duration principles [237-241] dictate that the work-rate to be used must be above CP (see supplementary material, 2.2 and fig. 8). It should be noted, however, that after training this work-rate may be below the pre-training CP (i.e. the patient may be able to perform the constant-load task for a relatively long period of time; see supplementary material, fig. 9). In COPD, there is increasing evidence that high-intensity constant-load endurance protocols with measurement of tlim, symptoms (e.g. dyspnoea and leg fatigue) and pertinent CPET variables (e.g. $V^{\prime} \mathrm{O}_{2}, V^{\prime} \mathrm{E}-V^{\prime} \mathrm{CO}_{2}$ slope respiratory frequency, IC, $f C)$ at "isotime" are superior to other protocols (e.g. $V^{\prime} \mathrm{O}_{2}$,peak on maximal intemental test, distance on 6-MWT) in the evaluation of the effects of therapeutic interventions [242].

In choosing an appropriate exercise test and a specific outcome marker, it is important to know the relationship between the specific exercise response and the local or systemic impairment intended to be modulated by the specific intervention. For example, MAN et al. [88] showed in COPD patients that leg effort assessed by subjective scoring on a Borg scale is a frequent symptom during incremental and endurance cycleergometry, but infrequent during incremental and endurance walking. This would imply that interventions targeted specifically at the skeletal muscles should preferably be evaluated by cycle-ergometry and not by walking tests. Indeed, a recent study [243] in COPD patients on systemic corticosteroid treatment showed that, relative to exercise training alone, supplementation with anabolic steroids was reflected in enhanced improvement in peak exercise capacity during incremental cycle-ergometry, but not in improved 6-MWD. A complicating factor in a multicomponent disease like most chronic cardiorespiratory diseases, such as COPD or CHF, may be that in individual patients different factors dominate impaired exercise capacity.

Effective rehabilitative interventions will not only be reflected in improved effort-dependent measures of exercise tolerance (e.g. $V^{\prime} \mathrm{O}_{2}$,peak, peak work-rate, $t$ lim) but will also yield altered physiological responses to identical exercise tasks. These alterations can be detected in both incremental and constantload cardiopulmonary exercise testing. Commonly used measures predictive of improved responses include dynamic hyperinflation, arterial lactate concentration, $V^{\prime} \mathrm{E}, V^{\prime} \mathrm{E} / V^{\prime} \mathrm{CO}_{2}$, breathing pattern and $\mathrm{Sp}, \mathrm{O}_{2}$.

Clearly, task-specificity also needs to be considered. For instance, interventions specifically aimed at improving upper extremity muscle endurance may be reflected in improved endurance time during arm-ergometry but not during cycleergometry.

For use in clinical trials or in individualised patient care, it is also important to know the minimal clinically important change in the different exercise tests. Using the 6-MWT, REDELMEIER et al. [244] proposed that a meaningful difference in performance was $54 \mathrm{~m}$ for patients with COPD. The minimum clinically important difference has not yet been published for the incremental or endurance shuttle walk test, or for cycleergometry.

Besides considering the information that can be retrieved from an exercise test, other factors need to be considered, such as standardisation of procedures to minimise variation, to avoid learning effects and to limit confounding influences related to 
motivation. This may be particularly relevant when the tests need to be used in multicentre clinical trials.

\section{Symptoms}

The severity of exertional dyspnoea, but also leg fatigue, is usually assessed by using a Borg scale or by a visual scale (VAS) $[245,246]$. The Borg scale has been used extensively to detect changes in dyspnoea after therapeutic interventions, particularly in COPD patients [247-254].

\section{Symptom-limited incremental test}

Until recently, most of the studies looked at changes in $V^{\prime} \mathrm{O}_{2}$,peak, peak work-rate and $\theta \mathrm{L}$ (and also $V^{\prime} \mathrm{E}$,max and maximum $f C$ ) with symptom-limited incremental CPET as primary outcome variables. It should be recalled that as peak work-rate is dependent on the work-rate increment rate (see supplementary material, 1.1 and fig. 1), interpretation of intervention-induced changes should take this into account. In most studies, the improvement in $V^{\prime} \mathrm{O}_{2}$,peak and/or peak work-rate is usually modest $(\sim 5 \%)$ and not unequivocally confirmed (e.g. the improvement in $V^{\prime} \mathrm{O}_{2}$, peak after rehabilitation in COPD), particularly in patients with the most advanced disease. In some controlled studies, $V^{\prime} \mathrm{O}_{2}$,peak increased significantly [255-258], while other studies failed to observe a significant amelioration $[259,260]$. $\theta \mathrm{L}$ has also been used as an outcome variable, particularly in CHF patients. As described earlier, the potential advantage of measuring $\theta \mathrm{L}$ during CPET is that maximal effort is not required; the results of the studies that have used $\theta \mathrm{L}$ are again not unequivocal. In COPD patients, controlled studies did not observe changes in maximal $f C$ or in maximal $V^{\prime} \mathrm{E}[258,259,261]$.

\section{Endurance time and physiological measurement at standardised time}

Endurance time during high-intensity exercise (i.e. above $\mathrm{CP}$; see supplementary material, 2.2) is increasingly used to assess exercise tolerance before and after a therapeutic intervention. Work-rates used in recent clinical studies were $75-80 \%$ of $V^{\prime} \mathrm{O}_{2}$,peak or peak work-rate measured during symptom-limited incremental CPET. In addition to tLIM, comparisons of symptom intensity (e.g. dyspnoea, leg effort) or physiological variables of interest (e.g. IC, $V^{\prime} \mathrm{E}, V^{\prime} \mathrm{O}_{2}, V^{\prime} \mathrm{E} / V^{\prime} \mathrm{CO}_{2}, f \mathrm{C}$ ) at a standardised time (isotime) have proved very useful in identifying the underlying physiological mechanisms responsible for increases in exercise tolerance induced by a particular intervention. Recent data from the literature support the notion that in COPD patients, endurance tests are more sensitive than other exercise protocols in detecting exercise-related physiological changes induced by interventions, and are thus very useful in clinical practice (fig. 4) [242].

In recent years, high-intensity constant-load protocols (e.g. 75$80 \%$ peak work-rate) have been used to demonstrate the positive effects of interventions such as bronchodilator therapy [252, 253, 262]; oxygen [263] and heliox [254] administration during exercise; bronchoscopic lung volume reduction [264]; and rehabilitation [265, 266]. By using this approach, it is possible to demonstrate a significant improvement in endurance time, mostly due to a reduction in lung dynamic hyperinflation and dyspnoea at isotime (table 3). The "highintensity" exercise endurance protocol should therefore now be considered the test of choice in evaluating the effects of therapeutic interventions in COPD.

\section{Moderate constant-load exercise}

Moderate constant-load tests (i.e. below $\theta \mathrm{L}$ ), on a cycleergometer or on a treadmill, lasting 6-8 $\mathrm{min}$ have been used to detect reductions in symptom scores and also in assessing the $V^{\prime} \mathrm{E}$ and $f C$ responses to training (see supplementary material, 2.1). These tests have been shown to be reliable and reproducible [267]. After exercise training, significant reductions in ventilation $[255,256,259,261,268]$ and lactate levels $[255,261,268]$ at identical submaximal work-rates have been observed. These findings suggest an improvement in aerobic metabolism $[255,269]$ and are in agreement with the observation of a significant increase in oxidative enzyme levels (16$40 \%$ ) in the quadriceps femoris muscle after a strenuous exercise programme [261]. Positive cardiac adaptation at submaximal exercise, identified by a lower $f C$, has been demonstrated in controlled [255-257, 270] and uncontrolled $[261,271]$ studies.

The extent of speeding of the response kinetics of $V^{\prime} \mathrm{E}$ and $V^{\prime} \mathrm{O}_{2}$ (see supplementary material, 2.1 and fig. 7) has also been used to detect improvements in oxygen transport and/or skeletal muscle metabolism after a specific intervention [255, 271, 272]. The $V^{\prime} \mathrm{O}_{2}$ kinetics reflect the overall efficiency of the oxygen transport system including muscle oxidative capacity and, in COPD, seem to be influenced by the oxygen delivery to the working muscles [273].

\section{Walking tests}

This approach has been used extensively both in patients with respiratory and in those with cardiac disease. The 6-MWT has been widely used in many large trials exploring the benefits of

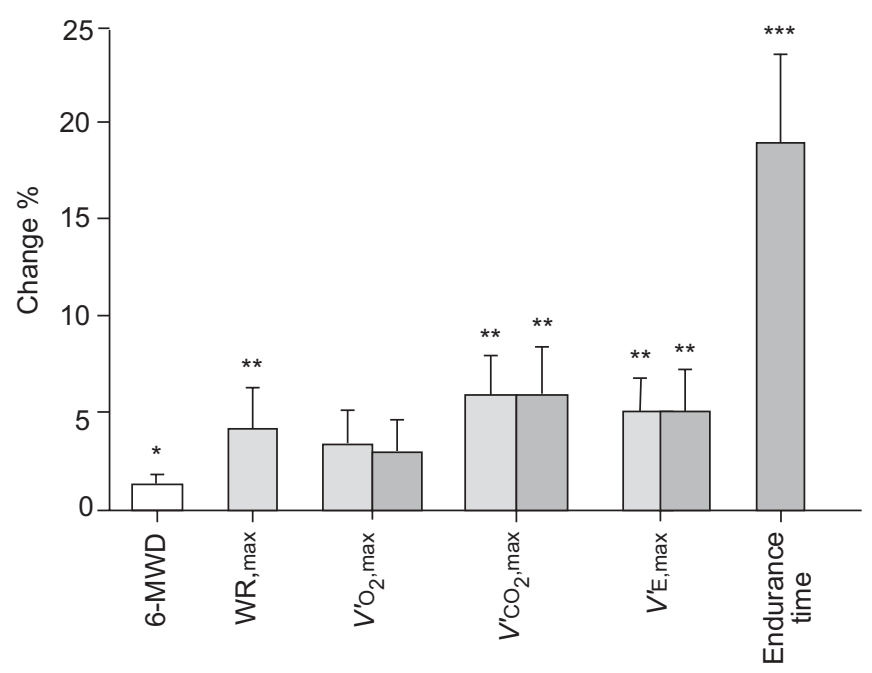

FIGURE 4. Changes in various measures of exercise performance after oxitropium bromide in three exercise tests. Changes are expressed as the percentage change versus placebo. Values are expressed as mean \pm SE. $\square$ : 6min walking distance (6-MWD); 1 : progressive cycle-ergometry; $\square:$ cycle endurance test. WR,max: maximal work-rate; $V^{\prime} \mathrm{O}_{2}$, max: maximal oxygen uptake; $V^{\prime} \mathrm{CO}_{2}$,max: maximal carbon dioxide output; $V$ 'E,max: maximal minute ventilation. * $p<0.05$; $* *: p<0.01 ; * * *: p<0.001$ versus placebo. Reproduced from [242] with permission from the publisher. 


\begin{tabular}{|c|c|c|c|c|c|}
\hline \multirow[t]{3}{*}{ TABLE 3} & \multicolumn{5}{|c|}{$\begin{array}{l}\text { Effects of different therapeutic interventions on endurance time, lung hyperinflation and dyspnoea in chronic } \\
\text { obstructive pulmonary disease }\end{array}$} \\
\hline & & \multicolumn{4}{|c|}{ Type of intervention [Ref.] } \\
\hline & & Tiotropium [252] & Oxygen [263] & Heliox [254] & Rehabilitation [266] \\
\hline \multicolumn{2}{|c|}{ Work-rate \% max } & 75 & 75 & 80 & 75 \\
\hline \multicolumn{2}{|c|}{$\Delta$ Endurance time $\%$} & +21 & +145 & +115 & +175 \\
\hline \multicolumn{2}{|c|}{$\Delta \mathrm{IC}$ at isotime $\%$} & +12 & +24 & +12 & +13 \\
\hline \multicolumn{2}{|c|}{$\Delta$ dyspnoea at isotime $\%$} & -14 & -40 & -25 & \\
\hline
\end{tabular}

FEV1: forced expiratory volume in one second; \% pred: \% of predicted value; IC: inspiratory capacity; $\Delta$ : changes at isotime expressed as a percentage of control condition.

rehabilitation, pharmaceutical intervention, oxygen supplementation and surgery in cardiorespiratory disease. The 6MWT has been shown to be a submaximal high-intensity constant-load test $[274,275]$. The test is used to investigate the effects of interventions on patients' walking endurance capacity. Measurements of $\mathrm{Sp}_{\mathrm{p}} \mathrm{O}_{2}$ and $f \mathrm{C}$ may be included to detect physiological improvements associated with improvements in exercise tolerance.

REDELMEIER et al. [244] proposed that a meaningful difference in performance for patients with COPD was $54 \mathrm{~m}$. This indicates the level at which the patient would appreciate an improvement in function capacity. TROOSTERS et al. [276] reported a mean increase of $52 \mathrm{~m}$ in a study of the short- and longer-term benefits of pulmonary rehabilitation delivered over a 6-month period. Results from similar rehabilitation studies confirm the magnitude of change [277, 278]. Pharmaceutical interventions have employed the 6-MWT as an outcome measure with some success [279]. The test has also been used as an outcome measure in rehabilitation for CHF [280] where a modest change in walking distance after 3 months of exercise training was observed.

The incremental SWT (ISWT) has not been extensively incorporated into pharmacological studies, but has been cited in a number of significant rehabilitation studies [281, 282]. There is considerable evidence that the test is sensitive to change. However, the minimum clinically important difference has not yet been published. A large rehabilitation study reported mean changes of $75.9 \mathrm{~m}$ [281]. In a large group of patients with COPD, the SWT was sensitive to the administration of formoterol and ipratopium bromide [283, 284]. The endurance SWT (ESWT) seems more sensitive to change after a course of rehabilitation than the ISWT. REVILL et al. [285] secured a mean increase in duration of $160 \%$, compared with the ISWT change of $32 \%$.

The administration of ambulatory oxygen has been described in many international guidelines. This is largely based upon the response to a standard field exercise test. The response is suggested to be either a $10 \%$ increase in distance or $10 \%$ reduction in dyspnoea with supplemental oxygen. The mode of exercise testing may be important. It appears that walking induces a greater degree of arterial desaturation than cycling $[54,86,88,286]$. The 6 -MWT has previously been shown to be sensitive to the administration of supplemental oxygen [287, 288]. The ISWT is responsive to the acute administration of oxygen [289]. However, the ESWT appears to demonstrate a greater magnitude of change to supplemental oxygen [290].

\section{EVIDENCE-BASED INDICATIONS TO EXERCISE TESTING IN CLINICAL PRACTICE}

The Task Force members felt that it was important to indicate the level of recommendation for the most relevant indications for exercise testing in clinical practice, on the basis of the arguments discussed and references provided. For this purpose an appropriate grading system, commonly used for recommendations in evidence-based guidelines, was utilised [291]. The grade of recommendation $(A=$ highest, $D=$ lowest), based on the levels of evidence is reported in table 4 for CPET and in table 5 for walking tests. It should be noted that with the use of this rigorous system, grade $\mathrm{A}$ is relatively rare and grade $\mathrm{B}$ is usually considered the best achievable.

Clear evidence now exists for the utility of CPET, as well as for other exercise test protocols, such as timed walking tests and constant-load tests, in evaluating the degree of exercise intolerance, the prognosis and the effects of therapeutic interventions in adult patients with chronic lung disease (COPD, ILD, PPH), in children and adults with $\mathrm{CF}$, in children and adults with EIB, in adults with CHF, and children and adolescents with CHDs. No consistent data are available in the literature on the clinical impact of CPET in diseases other than those mentioned above.

In clinical practice, CPET has not proven useful in diagnosing specific conditions. However, characteristic profiles of cardiopulmonary and gas-exchange response, discerned using CPET, may help in the differential diagnosis between pulmonary and cardiac limitation to exercise.

CPET should be considered the gold standard for evaluating maximal/symptom-limited exercise tolerance in patients with pulmonary and cardiac disease. Importantly, cardiopulmonary and gas-exchange response profiles measured at CPET are reproducible in the short term and in the longer term they can reflect disease progression. Field testing, often in combination with limited physiological measurements, is also a useful approach to assessing exercise intolerance in patients who may not need comprehensive CPET-based testing. CPET variables, 
TABLE 4 Indications for cardiopulmonary exercise testing in clinical practice

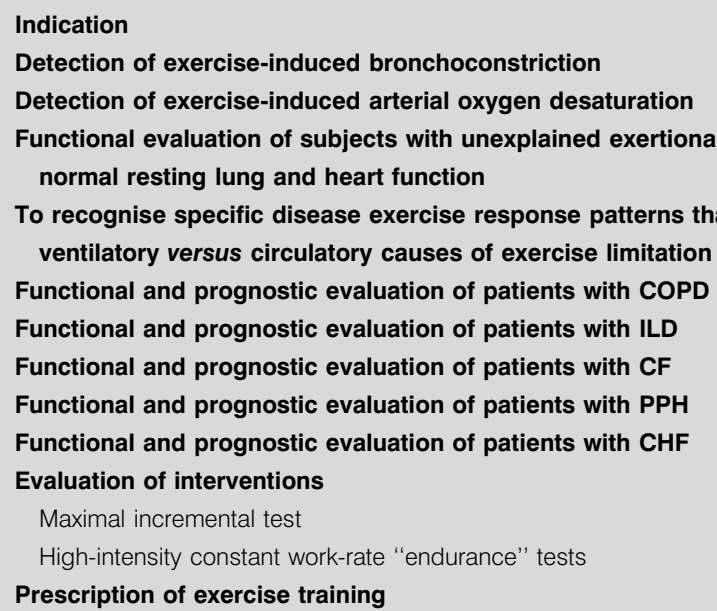

With the use of this grading system, $A$ is relatively rare and $B$ is usually considered the best achievable. COPD: chronic obstructive pulmonary disease; ILD: interstitial lung disease; CF: cystic fibrosis; PPH: primary pulmonary hypertension; CHF: chronic heart failure.

as well as distance covered during 6-MWT, have proven to be useful in the prognostic evaluation of patients with pulmonary and cardiac diseases, and these are now a main indication for exercise testing in these patient groups.

From the available literature, exercise tolerance and other CPET variables appear to be better predictors of prognosis than resting lung and/or cardiac function. However, studies have not yet been carried out to look at combinations of variables.

CPET variables, as well as distance covered during walking tests, have proven to be useful in clinical trials evaluating interventions in patients with pulmonary and cardiac diseases. This is now the main indication for exercise testing in these patient groups. It should be noted that, even if a clinical trial were originally designed to evaluate the effect of an intervention and the trial included exercise tolerance as one of the main outcomes, this can still provide indirect evidence of the interventional utility of exercise testing.

CPET variables as well as distance covered during walking tests have proven to be useful in the individual prescription of pulmonary rehabilitation and oxygen supplementation (by exercise testing pre- and post-intervention), and also for safety for subsequent exercise training (e.g. "healthy" elderly subjects). These should now be considered main indications for exercise testing in these patient groups.

$V^{\prime}$ O2,peak, 6-MWD and tLIM during high-intensity constantload endurance protocols have been proven to be superior to changes in resting lung and cardiac indices in the evaluation of the effects of interventions. High-intensity constant-load endurance protocols with measurement of tlim, symptoms and pertinent CPET variables at a standardised time (isotime) should be considered the test paradigm of choice, since they are able to detect significant improvement in exercise tolerance, which is often not the case for symptom-limited incremental exercise testing.

In conclusion, the evidence base on the value of exercise testing in functional evaluation, prognosis and discrimination of interventional changes in pulmonary and cardiac diseases has grown substantially in the past decade. However, as is evident from the summary tables (4 and 5), in some instances, the low power grades are reflective not so much of wellpowered statistical judgements as they are of weakness in the density of the relevant evidence base. Such areas should be seen as important priorities for future investigation.

\section{TABLE 5 Indications for 6-min and shuttle walking tests in clinical practice}

\section{Indication}

Diagnosis of exercise-induced arterial desaturation

Functional evaluation of patients with COPD, ILD, PPH, and CHF

Prognostic evaluation of patients with COPD, ILD, PPH and CHF

Functional evaluation of patients with CF

Prognostic evaluation of patients with COPD or CHF prior to surgery (LVRS, transplantation)

Evaluation of the benefits of therapeutic interventions (oxygen supplementation, rehabilitation, surgery)
Recommendation grade

B

B

C

C

With the use of this grading system, $\mathrm{A}$ is relatively rare and B is usually considered the best achievable. COPD: chronic obstructive pulmonary disease; ILD: interstitial lung disease; PPH: primary pulmonary hypertension; CHF: chronic heart failure; CF: cystic fibrosis; LVRS: lung-volume reduction surgery. 


\section{ACKNOWLEDGEMENTS}

The members of the Task Force on Clinical Exercise Testing are grateful to $\mathrm{R}$. Antonucci for her skilful assistance in the preparation of the manuscript.

The members of the Task Force are: P. Palange (Rome, Italy), S.A. Ward (Leeds, UK; chairmen), K.H. Carlsen (Oslo, Norway), R. Casaburi (Torrance, CA, USA), C.G. Gallagher (Dublin, Ireland), R. Gosselink (Leuven, Belgium), O'Donnell DE (Kingston, ON, Canada), L. Puente-Maestu (Madrid, Spain), A.M. Schols (Maastricht, The Netherlands), S. Singh (Leicester, UK) and B.J. Whipp (Leeds, UK).

\section{REFERENCES}

1 American Thoracic Society; American College of Chest Physicians, ATS/ACCP Statement on Cardiopulmonary Exercise Testing. Am J Respir Crit Care Med 2003; 167: 211-277.

2 ERS Task Force on Standardization of Clinical Exercise Testing, Clinical exercise testing with reference to lung diseases: indications, standardization and interpretation strategies. Eur Respir J 1997; 10: 2662-2689.

3 Roca J, Whipp BJ, eds. Clinical Exercise Testing. Eur Respir Mon 1997; 6.

4 Wasserman K, Hansen JE, Sue DY, Stringer W, Whipp BJ, eds. Principles of Exercise Testing and Interpretation, 4th Edn. Philadelphia, Lea \& Febiger, 2004.

5 Whipp BJ, Davis JA, Torres F, Wasserman K. A test to determine the parameters of aerobic function during exercise. J Appl Physiol 1981; 50: 217-221.

6 Porszasz J, Casaburi R, Somfay A, Woodhouse LJ, Whipp BJ. A treadmill ramp protocol using simultaneous changes in speed and grade. Med Sci Sports Exerc 2003; 35: 1596-1603.

7 Grant S, Aitchison T, Henderson E, et al. A comparison of the reproducibility and the sensitivity to change of visual analogue scales, Borg scales, and Likert scales in normal subjects during submaximal exercise. Chest 1999; 116: 1208-1217.

8 Laursen PB, Shing CM, Jenkins DG. Reproducibility of the cycling time to exhaustion at $V_{\mathrm{O}_{2}}$,peak in highly trained cyclists. Can J Appl Physiol 2003; 28: 605-615.

9 McLellan TM, Jacobs I. Reliability, reproducibility and validity of the individual anaerobic threshold. Eur J Appl Physiol Occup Physiol 1993; 67: 125-131.

10 Mercer TH. Reproducibility of blood lactate-anchored ratings of perceived exertion. Eur J Appl Physiol 2001; 85: 496-499.

11 Solway S, Brooks D, Lacasse $Y$, Thomas S. A qualitative systematic overview of the measurement properties of functional walk tests used in the cardiorespiratory domain. Chest 2001; 119: 256-270.

12 Casas A, Vilaro J, Rabinovich R, et al. Encouraged 6-min walking test indicates maximum sustainable exercise in COPD patients. Chest 2005; 128: 55-61.

13 Weber KT, Janicki JS, McElroy PA. Determination of aerobic capacity and the severity of chronic cardiac and circulatory failure. Circulation 1987; 76: VI40-VI45.

14 Enright PL, McBurnie MA, Bittner $\mathrm{V}$, et al. Cardiovascular Health Study. The 6-min walk test: a quick measure of functional status in elderly adults. Chest 2003; 123: 387-398.

15 Gibbons WJ, Fruchter N, Sloan S, Levy RD. Reference values for a multiple repetition 6-minute walk test in healthy adults older than 20 years. J Cardiopulm Rehabil 2001; 21: 87-93.

16 Troosters T, Gosselink R, Decramer M. Six minute walking distance in healthy elderly subjects. Eur Respir J 1999; 14: 270-274.

17 Sue DY, Hansen JE. Normal values in adults during exercise testing. Clin Chest Med 1984; 5: 89-98.

18 Wasserman K, VanKessel AL, Burton GG. Interaction of physiological mechanisms during exercise. J Appl Physiol 1967; 22: 71-85.

19 Gallagher CG. Exercise limitation and clinical exercise testing in chronic obstructive pulmonary disease. Clin Chest Med 1994; 15: 305-326.

20 Marciniuk DD, Gallagher CG. Clinical exercise testing in interstitial lung disease. Clin Chest Med 1994a; 15: 287-303.

21 Remme WJ, Swedberg K. Task Force for the Diagnosis and Treatment of Chronic Heart Failure, European Society of Cardiology. Guidelines for the diagnosis and treatment of chronic heart failure. Eur Heart J 2001; 22: 1527-1560.

22 Whipp BJ, Ward SA. Cardiopulmonary coupling during exercise. J Exp Biol 1982; 100: 175-193.

23 Jones NL, ed. Clinical Exercise Testing, 4th Edn. Philadelphia, WB Saunders, 1997; pp. 67-69.

24 Martinez FJ, Stanopoulos I, Acero R, Becker FS, Pickering R, Beamis JF. Graded comprehensive cardiopulmonary exercise testing in the evaluation of dyspnea unexplained by routine evaluation. Chest 1994; 105: 168-174.

25 Pratter MR, Curley FJ, Dubois J, Irwin RS. Cause and evaluation of chronic dyspnea in a pulmonary disease clinic. Arch Intern Med 1989; 149: 2277-2282.

26 Weisman IM, Zeballos RJ. Clinical evaluation of unexplained dyspnea. Cardiologia 1996; 41: 621-634.

27 Agostoni PG, Wasserman K, Perego GB, et al. Noninvasive measurement of stroke volume during exercise in heart failure patients. Clin Sci 2000; 98: 545-551.

28 Jones S, Elliott PM, Sharma S, McKenna WJ, Whipp BJ. Cardiopulmonary responses to exercise in patients with hypertrophic cardiomyopathy. Heart 1998; 80: 60-67.

29 Meyer K, Westbrook S, Schwaibold M, Hajric R, Peters K, Roskamm H. Short-term reproducibility of cardiopulmonary measurements during exercise testing in patients with severe chronic heart failure. Am Heart J 1997; 134: 20-26.

30 McElroy PA, Janicki JS, Weber KT. Cardiopulmonary exercise testing in congestive heart failure. Am J Cardiol 1988; 62: 35A-40A.

31 Belardinelli R, Lacalaprice F, Carle F, et al. Exerciseinduced myocardial ischaemia detected by cardiopulmonary exercise testing. Eur Heart J 2003; 24: 1304-1313.

32 Diaz O, Villafranca C, Ghezzo H, et al. Breathing pattern and gas exchange at peak exercise in COPD patients with and without tidal flow limitation at rest. Eur Respir J 2001; 17: $1120-1127$.

33 Gardner WN, Meah MS, Bass C. Controlled study of respiratory responses during prolonged measurement in 
patients with chronic hyperventilation. Lancet 1986; 2: 826-830.

34 Kinnula VL, Sovijarvi AR. Elevated ventilatory equivalents during exercise in patients with hyperventilation syndrome. Respiration 1993; 60: 273-278.

35 Jack S, Rossiter HB, Pearson MG, Ward SA, Warburton JC, Whipp BJ. Ventilatory responses to inhaled carbondioxide, hypoxia and exercise in idiopathic hyperventilation. Am J Respir Crit Care Med 2004; 170: 118-125.

36 Hammo AH, Weinberger MM. Exercise-induced hyperventilation: a pseudoasthma syndrome. Ann Allergy Asthma Immunol 1999; 82: 574-578.

37 Gardin JM, Isner JM, Ronan JA Jr, Fox SM 3rd. Pseudoischemic "false positive" S-T segment changes induced by hyperventilation in patients with mitral valve prolapse. Am J Cardiol 1980; 45: 952-958.

38 Epstein SK, Zilberberg MD, Jacoby C, Ciubotaru RL, Kaplan LM. Response to symptom-limited exercise in patients with the hepatopulmonary syndrome. Chest 1998; 114: 736-741.

39 Kahaly G, Hellermann J, Mohr-Kahaly S, Treese N. Impaired cardiopulmonary exercise capacity in patients with hyperthyroidism. Chest 1996; 109: 57-61.

40 MacGowan GA, Panzak G, Murali S. Exercise-related ventilatory abnormalities are more specific for functional impairment in chronic heart failure than reduction in peak exercise oxygen consumption. J Heart Lung Transplant 2001; 20: 1167-1173.

41 Riley M, Nicholls DP, Nugent AM, et al. Respiratory gas exchange and metabolic responses during exercise in McArdle's disease. J Appl Physiol 1993; 75: 745-754.

42 Rubin SA, Brown HV. Ventilation and gas exchange during exercise in severe chronic heart failure. Am Rev Respir Dis 1984; 129: S63-S64.

43 Taivassalo $T$, Jensen TD, Kennaway N, DiMauro S, Vissing J, Haller RG. The spectrum of exercise tolerance in mitochondrial myopathies: a study of 40 patients. Brain 2003; 126: 413-423.

44 Lugliani R, Whipp BJ, Wasserman K. Doxapram hydrochloride: a respiratory stimulant for patients with primary alveolar hypoventilation. Chest 1979; 76: 414-419.

45 Shea SA, Andres LP, Shannon DC, Banzett RB. Ventilatory responses to exercise in humans lacking ventilatory chemosensitivity. J Physiol 1993; 468: 623-640.

46 Paton JY, Swaminathan S, Sargent CW, Hawksworth A, Keens TG. Ventilatory response to exercise in children with congenital central hypoventilation syndrome. Am Rev Respir Dis 1993; 147: 1185-1191.

47 Pinto AC, Evangelista T, de Carvalho M, Paiva T, de Lurdes Sales-Luis M. Respiratory disorders in ALS: sleep and exercise studies. J Neurol Sci 1999; 169: 61-68.

48 Hansen JE, Sue DY, Wasserman K. Predicted values for clinical exercise testing. Am Rev Respir Dis 1984; 129:S49-S55.

49 Whipp BJ, Wasserman K. Alveolar-arterial gas tension differences during graded exercise. J Appl Physiol 1969; 27: 361-365.

50 Badesch DB, Abman SH, Ahearn GS, et al. Medical therapy for pulmonary arterial hypertension: ACCP evidence-based clinical practice guidelines. Chest 2004; 126: 35S-62S.
51 Lee YC, Singh B, Pang SC, de Klerk NH, Hillman DR, Musk AW. Radiographic (ILO) readings predict arterial oxygen desaturation during exercise in subjects with asbestosis. Occup Environ Med 2003; 60: 201-206.

52 Lama VN, Flaherty KR, Toews GB, et al. Prognostic value of desaturation during a 6-minute walk test in idiopathic interstitial pneumonia. Am J Respir Crit Care Med 2003; 168: 1084-1090.

53 Mak VH, Bugler JR, Roberts CM, Spiro SG. Effect of arterial oxygen desaturation on six minute walk distance, perceived effort, and perceived breathlessness in patients with airflow limitation. Thorax 1993; 48: 33-38.

54 Poulain M, Durand F, Palomba B, et al. 6-minute walk testing is more sensitive than maximal incremental cycle testing for detecting oxygen desaturation in patients with COPD. Chest 2003; 123: 1401-1407.

55 Rowell LB, Shepherd JT, eds. Handbook of Physiology. Section 12: Exercise: Regulation and Integration of Multiple Systems. Bethesda, American Physiological Society, 1996.

56 Maughan R, Gleeson M, Greenhaff PL, eds. Biochemistry of Exercise and Training. Oxford, Oxford University Press, 1997.

57 Richardson RS, Haseler LJ, Nygren AT, Bluml S, Frank LR. Local perfusion and metabolic demand during exercise: a noninvasive MRI method of assessment. J Appl Physiol 2001; 91: 1845-1853.

58 Rossiter HB, Howe FA, Ward SA. Intramuscular [PCr] and pulmonary $V^{\prime} \mathrm{O}_{2}$ kinetics: implications for control of muscle oxygen consumption. In: Jones AM, Poole DC, eds. Oxygen Uptake Kinetics in Health and Disease. New York, Routledge, 2005; pp. 154-184.

59 Elliot DL, Buist NR, Goldberg L, Kennaway NG, Powell BR, Kuehl KS. Metabolic myopathies: evaluation by graded exercise testing. Medicine 1989; 68: 163-172.

60 Gross M, Gresser U. Ergometer exercise in myoadenylate deaminase deficient patients. Clin Investig 1993; 71: 461-465.

61 Cooper CB, Storer TW, eds. Exercise testing an interpretation: A practical approach. Cambrige, Cambridge University Press, 2001.

62 Borg GA. Psychophysical basis of perceived exertion. Med Sci Sports Exerc 1982; 14: 377-381.

63 Hamilton AL, Killian KJ, Summers E, Jones NL. Symptom intensity and subjective limitation to exercise in patients with cardiorespiratory disorders. Chest 1996; 110: 1255-1263.

64 Lainchbury JG, Richards AM. Exercise testing in the assessment of chronic congestive heart failure. Heart 2002; 88: 538-543.

65 Messner-Pellenc P, Ximenes C, Brasileiro CF, Mercier J, Grolleau R, Prefaut CG. Cardiopulmonary exercise testing. Determinants of dyspnea due to cardiac or pulmonary limitation. Chest 1994; 106: 354-360.

66 Palange P, Carlone S, Forte S, Galassetti P, Serra P. Cardiopulmonary exercise testing in the evaluation of patients with ventilatory vs circulatory causes of reduced exercise tolerance. Chest 1994; 105: 1122-1126.

67 Working Group on Cardiac Rehabilitation and Exercise Physiology and Working Group on Heart Failure of the European Society of Cardiology, Recommendations for 
exercise testing in chronic heart failure patients. Eur Heart J 2001; 22: 37-45.

68 Gibbons RJ, Balady GJ, Bricker JT, et al. ACC/AHA 2002 guideline update for exercise testing: summary article: a report of the American College of Cardiology/American Heart Association Task Force on Practice Guidelines (Committee to Update the 1997 Exercise Testing Guidelines). Circulation 2002; 106: 1883-1892.

69 Markowitz DH, Systrom DM. Diagnosis of pulmonary vascular limit to exercise by cardiopulmonary exercise testing. J Heart Lung Transplant 2004; 23: 88-95.

70 Bauerle O, Younes $\mathrm{M}$. Role of ventilatory response to exercise in determining exercise capacity in COPD. J Appl Physiol 1995; 79: 1870-1877.

71 Cotes JE, Zejda J, King B. Lung function impairment as a guide to exercise limitation in work-related lung disorders. Am Rev Respir Dis 1988; 137: 1089-1093.

72 Sue DY. Exercise testing in the evaluation of impairment and disability. Clin Chest Med 1994; 15: 369-387.

73 Sue DY, Oren A, Hansen JE, Wasserman K. Diffusing capacity for carbon monoxide as a predictor of gas exchange during exercise. $N$ Engl J Med 1987; 316: 1301-1306.

74 Brown SE, Fischer CE, Stansbury DW, Light RW. Reproducibility of $\mathrm{VO}_{2}$, max in patients with chronic airflow obstruction. Am Rev Respir Dis 1985; 131: 435-438.

75 Cox NJ, Hendriks JC, Binkhorst RA, Folgering HT, van Herwaarden CL. Reproducibility of incremental maximal cycle ergometer tests in patients with mild to moderate obstructive lung diseases. Lung 1989; 167: 129-133.

76 Muza SR, Silverman MT, Gilmore GC, Hellerstein HK, Kelsen SG. Comparison of scales used to quantitate the sense of effort to breathe in patients with chronic obstructive pulmonary disease. Am Rev Respir Dis 1990; 141: 909-913.

77 Killian KJ, Leblanc P, Martin DH, Summers E, Jones NL, Campbell EJ. Exercise capacity and ventilatory, circulatory, and symptom limitation in patients with chronic airflow limitation. Am Rev Respir Dis 1992; 146: 935-940.

78 O'Donnell DE, Webb KA. Mechanisms of dyspnea in COPD. In: Mahler DA, O'Donnell DE, eds. Dyspnea: Mechanisms, Measurement, and Management. 2nd Edn. Lung Biology in Health and Disease Series, Volume 208. Boca Raton, Taylor \& Francis Group, 2005; pp. 29-58.

79 O'Donnell DE, D'Arsigny C, Fitzpatrick M, Webb KA. Exercise hypercapnia in advanced chronic obstructive pulmonary disease: the role of lung hyperinflation. Am J Respir Crit Care Med 2002; 166: 663-668.

80 Puente-Maestu L, García de Pedro J, Martínez-Abad Y, Ruíz de Oña JM, Llorente D, Cubillo JM. Dyspnea, ventilatory pattern, and changes in dynamic hyperinflation related to the intensity of constant work rate exercise in COPD. Chest 2005; 128: 651-656.

81 O'Donnell DE, Revill SM, Webb KA. Dynamic hyperinflation and exercise intolerance in chronic obstructive pulmonary disease. Am J Respir Crit Care Med 2001; 164: 770-777.

82 Yan S, Kaminski D, Sliwinski P. Reliability of inspiratory capacity for estimating end-expiratory lung volume changes during exercise in patients with chronic obstructive pulmonary disease. Am J Respir Crit Care Med 1997; 156: 55-59.
83 Ries AL, Farrow JT, Clausen JL. Pulmonary function tests cannot predict exercise-induced hypoxemia in chronic obstructive pulmonary disease. Chest 1988; 93: 454-459.

84 Knower MT, Dunagan DP, Adair NE, Chin R Jr. Baseline oxygen saturation predicts exercise desaturation below prescription threshold in patients with chronic obstructive pulmonary disease. Arch Intern Med 2001; 161: 732-736.

85 Hadeli KO, Siegel EM, Sherrill DL, Beck KC, Enright PL. Predictors of oxygen desaturation during submaximal exercise in 8,000 patients. Chest 2001; 120: 88-92.

86 Palange $\mathrm{P}$, Forte S, Onorati P, Manfredi F, Serra P, Carlone S. Ventilatory and metabolic adaptations to walking and cycling in patients with COPD. J Appl Physiol 2000; 88: 1715-1720.

87 Turner SE, Eastwood PR, Cecins NM, Hillman DR, Jenkins SC. Physiologic responses to incremental and self-paced exercise in COPD: a comparison of three tests. Chest 2004; 126: 766-773.

88 Man WD, Soliman MG, Gearing J, et al. Symptoms and quadriceps fatigability after walking and cycling in chronic obstructive pulmonary disease. Am J Respir Crit Care Med 2003; 168: 562-567.

89 Sterk PJ, Fabbri LM, Quanjer PH, et al. Airway responsiveness. Standardized challenge testing with pharmacological, physical and sensitizing stimuli in adults. Report Working Party Standardization of Lung Function Tests. European Community for Steel and Coal. Official statement of the European Respiratory Society. Eur Respir J 1993; 6: S53-S83.

90 Crapo RO, Casaburi R, Coates AL, et al. Guidelines for methacholine and exercise challenge testing - 1999. Am J Respir Crit Care Med 2000; 161: 309-329.

91 Eggleston PA. A comparison of the asthmatic response to methacholine and exercise. J Allergy Clin Immunol 1979; 63: 104-110.

92 Eliasson AH, Phillips YY, Rajagopal KR, Howard RS. Sensitivity and specificity of bronchial provocation testing. An evaluation of four techniques in exerciseinduced bronchospasm. Chest 1992; 102: 347-355.

93 Fourie PR, Joubert JR. Determination of airway hyperreactivity in asthmatic children: a comparison among exercise, nebulized water, and histamine challenge. Pediatr Pulmonol 1988; 4: 2-7.

94 Lin CC, Wu JL, Huang WC, Lin CY. A bronchial response comparison of exercise and methacholine in asthmatic subjects. J Asthma 1991; 28: 31-40.

95 Shapiro GG. Methacholine challenge-relevance for the allergic athlete. J Allergy Clin Immunol 1984; 73: 670-675.

96 Vasar M, Braback L, Julge K, Knutsson A, Riikjarv MA, Bjorksten B. Prevalence of bronchial hyperreactivity as determined by several methods among Estonian school children. Pediatr Allergy Immunol 1996; 7: 141-146.

97 Godfrey S, Springer C, Bar-Yishay E, Avital A. Cut-off points defining normal and asthmatic bronchial reactivity to exercise and inhalation challenges in children and young adults. Eur Respir J 1999; 14: 659-668.

98 Holzer K, Brukner P, Douglass J. Evidence-based management of exercise-induced asthma. Curr Sports Med Rep 2002; 1: 86-92. 
99 Cockcroft DW, Murdock KY, Berscheid BA, Gore BP. Sensitivity and specificity of histamine PC20 determination in a random selection of young college students. $J$ Allergy Clin Immunol 1992; 89: 23-30.

100 Anderson SD, Silverman M, Tai E, Godfrey S. Specificity of exercise in exercise-induced asthma. BMJ 1971; 4: 814-815.

101 Godfrey S, Silverman M, Anderson SD. The use of the treadmill for assessing exercise-induced asthma and the effect of varying the severity and duration of exercise. Pediatrics 1975; 56: 893-898.

102 Deal EC Jr, McFadden ER Jr, Ingram RH Jr, Strauss RH, Jaeger JJ. Role of respiratory heat exchange in production of exercise-induced asthma. J Appl Physiol 1979; 46: 467-475.

103 Lee TH, Anderson SD. Heterogeneity of mechanisms in exercise-induced asthma. Thorax 1985; 40: 481-487.

104 Noviski N, Bar-Yishay E, Godfrey S. Exercise intensity determines and climatic conditions modify the severity of exercise-induced asthma. Am Rev Respir Dis 1987; 136: 592-594.

105 Carlsen KH, Engh G, Mørk M. Exercise induced bronchoconstriction depends on exercise load. Respir Med 2000; 94: 750-755.

106 Waalkens HJ, van Essen-Zandvliet EE, Gerritsen J, Duiverman EJ, Kerrebijn KF, Knol K. The effect of an inhaled corticosteroid (budesonide) on exercise-induced asthma in children. Dutch CNSLD Study Group. Eur Respir J 1993; 6: 652-656.

107 Jonasson G, Carlsen KH, Hultquist C. Low-dose budesonide improves exercise-induced bronchospasm in schoolchildren. Pediatr Allergy Immunol 2000; 11: 120-125.

108 Pauwels R, Joos G, Van der Straeten M. Bronchial hyperresponsiveness is not bronchial asthma. Clin Allergy 1988; 18: 317-321.

109 Carlsen KH, Engh G, Mørk M, Schrøder E. Cold air inhalation and exercise-induced bronchoconstriction in relationship to metacholine bronchial responsiveness: different patterns in asthmatic children and children with other chronic lung diseases. Respir Med 1998; 92: 308-315.

110 Godfrey S, Springer C, Noviski N, Maayan C, Avital A. Exercise but not metacholine differentiates asthma from chronic lung disease in children. Thorax 1991; 46: 488-492.

111 Carlsen KH, Bech R, Oseid S, Schrøder E. Bronchial reactivity measured by exercise-induced asthma test and PC-20-histamine: A comparison of two methods. In: Morehouse CA, ed. Children and Exercise XII. Champaign, Human Kinetics Publishers Inc., 1986; pp. 295-300.

112 Keogh BA, Lakatos E, Price D, Crystal RG. Importance of the lower respiratory tract in oxygen transfer. Exercise testing in patients with interstitial and destructive lung disease. Am Rev Respir Dis 1984; 129: S76-S80.

113 Marciniuk DD, Watts RE, Gallagher CG. Reproducibility of incremental maximal cycle ergometer testing in patients with restrictive lung disease. Thorax 1993; 48: 894-898.

114 Fulmer JD, Roberts WC, von Gal ER, Crystal RG. Morphologic-physiologic correlates of the severity of fibrosis and degree of cellularity in idiopathic pulmonary fibrosis. J Clin Invest 1979; 63: 665-676.
115 Lama VN, Martinez FJ. Resting and exercise physiology in interstitial lung diseases. Clin Chest Med 2004; 25: 435-453.

116 Younes M. Determinants of thoracic excursions. In: Whipp BJ, Wasserman K, eds. Pulmonary Physiology and Pathophysiology of Exercise. New York, Dekker, 1991; pp. 1-65.

117 Marciniuk DD, Sridhar G, Clemens RE, Zintel TA, Gallagher CG. Lung volumes and expiratory flow limitation during exercise in interstitial lung disease. J Appl Physiol 1994b; 77: 963-973.

118 O'Donnell DE, Chau LK, Webb KA. Qualitative aspects of exertional dyspnea in patients with interstitial lung disease. J Appl Physiol 1998; 84: 2000-2009.

119 Chetta A, Aiello M, Foresi A, et al. Relationship between outcome measures of six-minute walk test and baseline lung function in patients with interstitial lung disease. Sarcoidosis Vasc Diffuse Lung Dis 2001; 18: 170-175.

120 Bush A, Busst CM. Cardiovascular function at rest and on exercise in patients with cryptogenic fibrosing alveolitis. Thorax 1988; 43: 276-283.

121 Spiro SG, Dowdeswell IR, Clark TJ. An analysis of submaximal exercise responses in patients with sarcoidosis and fibrosing alveolitis. Br J Dis Chest 1981; 75: 169-180.

122 Hawrylkiewicz I, Izdebska-Makosa Z, Grebska E, Zielinski J. Pulmonary haemodynamics at rest and on exercise in patients with idiopathic pulmonary fibrosis. Bull Eur Physiopathol Respir 1982; 18: 403-410.

123 Weitzenblum E, Ehrhart M, Rasaholinjanahary J, Hirth C. Pulmonary hemodynamics in idiopathic pulmonary fibrosis and other interstitial pulmonary diseases. Respiration 1983; 44: 118-127.

124 Gibbons WJ, Levy RD, Nava S, et al. Subclinical cardiac dysfunction in sarcoidosis. Chest 1991; 100: 44-50.

125 Deboeck G, Niset G, Lamotte M, Vachiery JL, Naeije R. Exercise testing in pulmonary arterial hypertension and in chronic heart failure. Eur Respir J 2004; 23: 747-751.

126 Mohsenifar Z, Tashkin DP, Levy SE, Bjerke RD, Clements PJ, Furst D. Lack of sensitivity of measurements of VD/VT at rest and during exercise in detection of hemodynamically significant pulmonary vascular abnormalities in collagen vascular disease. Am Rev Respir Dis 1981; 123: 508-512.

127 Wensel R, Opitz CF, Anker SD, et al. Assessment of survival in patients with primary pulmonary hypertension: importance of cardiopulmonary exercise testing. Circulation 2002; 106: 319-324.

128 Cotes JE. Exchange of gas in the lung. In: Cotes JE, ed. Lung Function: Assessment and Application in Medicine. 5th Edn. Oxford, Blackwell Scientific Publications, 1993; pp. 263-298.

129 Rubin LJ. Primary pulmonary hypertension. Chest 1993; 104: 236-250.

130 Hansen JE, Sun XG, Yasunobu Y, et al. Reproducibility of cardiopulmonary exercise measurements in patients with pulmonary arterial hypertension. Chest 2004; 126: 816-824.

131 Sun XG, Hansen JE, Oudiz RJ, Wasserman K. Gas exchange detection of exercise-induced right-to-left shunt in patients with primary pulmonary hypertension. Circulation 2002; 105: 54-60.

132 Jones PW, Huszczuk A, Wasserman K. Cardiac output as a controller of ventilation through changes in right ventricular load. J Appl Physiol 1982; 53: 218-224. 
133 Aguggini G, Clement MG, Widdicombe JG. Lung reflexes affecting the larynx in the pig, and the effect of pulmonary microembolism. Q J Exp Physiol 1987; 72: 95-104.

134 Wilson JR, Mancini DM. Factors contributing to the exercise limitation of heart failure. J Am Coll Cardiol 1993; 22: 93A-98A.

135 Faggiano P, D'Aloia A, Gualeni A, Giordano A. Relative contribution of resting haemodynamic profile and lung function to exercise tolerance in male patients with chronic heart failure. Heart 2001; 85: 179-184.

136 Kraemer MD, Kubo SH, Rector TS, Brunsvold N, Bank AJ. Pulmonary and peripheral vascular factors are important determinants of peak exercise oxygen uptake in patients with heart failure. J Am Coll Cardiol 1993; 21: 641-648.

137 Chauhan A, Sridhar G, Clemens R, Krishnan B, Marciniuk DD, Gallagher CG. Role of respiratory function in exercise limitation in chronic heart failure. Chest 2000; 118: 53-60.

138 Gitt AK, Wasserman K, Kilkowski C, et al. Exercise anaerobic threshold and ventilatory efficiency identify heart failure patients for high risk of early death. Circulation 2002; 106: 3079-3084.

139 Chua T, Ponikowski P, Harrington D, et al. Clinical correlates and prognostic significance of the ventilatory response to exercise in chronic heart failure. J Am Coll Cardiol 1997; 29: 1585-1590.

140 Ponikowski P, Francis DP, Piepoli MF, et al. Enhanced ventilatory response to exercise in patients with chronic heart failure and preserved exercise tolerance: marker of abnormal cardiorespiratory reflex control and predictor of poor prognosis. Circulation 2001; 103: 967-972.

141 Lehmann G, Kolling K. Reproducibility of cardiopulmonary exercise parameters in patients with valvular heart disease. Chest 1996; 110: 685-692.

142 Kronenberg MW, Konstam MA, Edens TR, et al. Factors influencing exercise performance in patients with left ventricular dysfunction. SOLVD Investigators. Studies of Left Ventricular Dysfunction. J Card Fail 1998; 4: 159-167.

143 Neuberg GW, Friedman SH, Weiss MB, Herman MV. Cardiopulmonary exercise testing. The clinical value of gas exchange data. Arch Intern Med 1988; 148: 2221-2226.

144 Costanzo MR, Augustine S, Bourge R, et al. Selection and treatment of candidates for heart transplantation. A statement for health professionals from the Committee on Heart Failure and Cardiac Transplantation of the Council on Clinical Cardiology, American Heart Association. Circulation 1995; 92: 3593-3612.

145 Mudge GH, Goldstein S, Addonizio LJ, et al. 24th Bethesda Conference: Cardiac transplantation. Task Force 3: Recipient guidelines/prioritization. I Am Coll Cardiol 1993; 22: 21-31.

146 Opasich C, Pasini E, Aquilani R, et al. Skeletal muscle function at low work level as a model for daily activities in patients with chronic heart failure. Eur Heart J 1997; 18: 1626-1631.

147 Steele IC, Moore A, Nugent AM, Riley MS, Campbell NP, Nicholls DP. Non-invasive measurement of cardiac output and ventricular ejection fractions in chronic cardiac failure: relationship to impaired exercise tolerance. Clin Sci 1997; 93: 195-203.
148 Haouzi P, Huszczuk A, Porszasz J, Chalon B, Wasserman K, Whipp BJ. Femoral vascular occlusion and ventilation during recovery from heavy exercise. Respir Physiol 1993; 94: 137-150.

149 Ichiyama RM, Waldrop TG, Iwamoto GA. Neurons in and near insular cortex are responsive to muscular contraction and have sympathetic and/or cardiac-related discharge. Brain Res 2004; 1008: 273-277.

150 Scott AC, Wensel R, Davos CH, et al. Chemical mediators of the muscle ergoreflex in chronic heart failure: a putative role for prostaglandins in reflex ventilatory control. Circulation 2002; 106: 214-220.

151 Scott AC, Wensel R, Davos $\mathrm{CH}$, et al. Skeletal muscle reflex in heart failure patients: role of hydrogen. Circulation 2003; 107: 300-306.

152 Sinoway LI, Li J. A perspective on the muscle reflex: implications for congestive heart failure. J Appl Physiol 2005; 99: 5-22.

153 Kostreva DR, Zuperku EJ, Purtock RV, Coon RL, Kampine JP. Sympathetic afferent nerve activity of right heart origin. Am J Physiol 1975; 229: 911-915.

154 Haouzi P, Marchal F, Huszczuk A. Muscle perfusion and control of breathing. Is there a neural link? Adv Exp Med Biol 1995; 393: 363-368.

155 Dimopoulou I, Tsintzas OK, Alivizatos PA, Tzelepis GE. Pattern of breathing during progressive exercise in chronic heart failure. Int J Cardiol 2001; 81: 117-121.

156 Witte KK, Thackray SD, Nikitin NP, Cleland JG, Clark AL. Pattern of ventilation during exercise in chronic heart failure. Heart 2003; 89: 610-614.

157 Agostoni P, Pellegrino R, Conca C, Rodarte JR, Brusasco V. Exercise hyperpnea in chronic heart failure: relationships to lung stiffness and expiratory flow limitation. J Appl Physiol 2002; 92: 1409-1416.

158 Schroeder CA, Balfe DL, Khan SS, Mohsenifar Z. Airflow limitation and breathing strategy in congestive heart failure patients during exercise. Respiration 2003; 70: 137-142.

159 Evans SA, Watson L, Cowley AJ, Johnston ID, Kinnear WJ. Static lung compliance in chronic heart failure: relation with dyspnoea and exercise capacity. Thorax 1995; 50: 245-248.

160 Evans SA, Kinnear WJ, Watson L, Hawkins M, Cowley AJ, Johnston ID. Breathlessness and exercise capacity in heart failure: the role of bronchial obstruction and responsiveness. Int J Cardiol 1996; 57: 233-240.

161 Ben-Dov I, Sietsema KE, Casaburi R, Wasserman K. Evidence that circulatory oscillations accompany ventilatory oscillations during exercise in patients with heart failure. Am Rev Respir Dis 1992; 145: 776-781.

162 Leite JJ, Mansur AJ, de Freitas HF, et al. Periodic breathing during incremental exercise predicts mortality in patients with chronic heart failure evaluated for cardiac transplantation. J Am Coll Cardiol 2003; 41: 2175-2181.

163 Yajima T, Koike A, Sugimoto K, Miyahara Y, Marumo F, Hiroe M. Mechanism of periodic breathing in patients with cardiovascular disease. Chest 1994; 106: 142-146.

164 James FW, Blomqvist CG, Freed MD, et al. Standards for exercise testing in the pediatric age group. American Heart Association Council on Cardiovascular Disease in the Young. Ad hoc committee on exercise testing. Circulation 1982; 66: 1377A-1397A. 
165 Fredriksen PM, Ingjer F, Nystad W, Thaulow E. Aerobic endurance testing of children and adolescents--a comparison of two treadmill-protocols. Scand J Med Sci Sports 1998; 8: 203-207.

166 Fredriksen PM, Ingjer F, Nystad W, Thaulow E. A comparison of $\mathrm{VO}_{2}$ (peak) between patients with congenital heart disease and healthy subjects, all aged 8-17 years. Eur J Appl Physiol Occup Physiol 1999; 80: 409-416.

167 McManus A, Leung M. Maximising the clinical use of exercise gaseous exchange testing in children with repaired cyanotic congenital heart defects: the development of an appropriate test strategy. Sports Med 2000; 29: 229-244.

168 Reybrouck T, Mertens L, Brusselle S, et al. Oxygen uptake versus exercise intensity: a new concept in assessing cardiovascular exercise function in patients with congenital heart disease. Heart 2000; 84: 46-52.

169 Gurses HN, Gurses A, Arikan H. Exercise testing in children with congenital heart disease before and after surgical treatment. Pediatr Cardiol 1991; 12: 20-23.

170 Laukkanen JA, Lakka TA, Rauramaa $\mathrm{R}$, et al. Cardiovascular fitness as a predictor of mortality in men. Arch Intern Med 2001; 161: 825-831.

171 Katzmarzyk PT, Church TS, Blair SN. Cardiorespiratory fitness attenuates the effects of the metabolic syndrome on all-cause and cardiovascular disease mortality in men. Arch Intern Med 2004; 164: 1092-1097.

172 Sherman SE, D'Agostino RB, Cobb JL, Kannel WB. Does exercise reduce mortality rates in the elderly? Experience from the Framingham Heart Study. Am Heart J 1994; 128: 965-972.

173 Wei M, Kampert JB, Barlow CE, et al. Relationship between low cardiorespiratory fitness and mortality in normal-weight, overweight, and obese men. JAMA 1999; 282: 1547-1553.

174 Anthonisen NR, Wright EC, Hodgkin JE. Prognosis in chronic obstructive pulmonary disease. Am Rev Respir Dis 1986; 133: 14-20.

175 Schols AM, Slangen J, Volovics L, Wouters EF. Weight loss is a reversible factor in the prognosis of chronic obstructive pulmonary disease. Am J Respir Crit Care Med 1998; 157: 1791-1797.

176 Landbo C, Prescott E, Lange P, Vestbo J, Almdal TP. Prognostic value of nutritional status in chronic obstructive pulmonary disease. Am J Respir Crit Care Med 1999; 160: 1856-1861.

177 Casanova C, Cote C, de Torres JP, et al. Inspiratory-tototal lung capacity ratio predicts mortality in patients with chronic obstructive pulmonary disease. Am J Respir Crit Care Med 2005; 171: 591-597.

178 Fletcher EC, Donner CF, Midgren B, et al. Survival in COPD patients with a daytime $\mathrm{PaO}_{2}$ greater than $60 \mathrm{mmHg}$ with and without nocturnal oxyhemoglobin desaturation. Chest 1992; 101: 649-655.

179 Oswald-Mammosser M, Weitzenblum E, Quoix E, et al. Prognostic factors in COPD patients receiving longterm oxygen therapy. Importance of pulmonary artery pressure. Chest 1995; 107: 1193-1198.

180 Chodosowska E, Skwarski K, Zielinski J. Mixed venous blood oxygen tension is not a good predictor of survival in patients with chronic obstructive lung disease. Eur J Respir Dis 1987; 71: 233-238.

181 Nishimura K, Izumi T, Tsukino M, Oga T. Dyspnea is a better predictor of 5-year survival than airway obstruction in patients with COPD. Chest 2002; 121: 1434-1440.

182 Casaburi R. Skeletal muscle dysfunction in chronic obstructive pulmonary disease. Med Sci Sport Exerc 2001; 33: S662-S670.

183 Palange $\mathrm{P}$, Wagner PD. The skeletal muscle in chronic respiratory diseases, summary of the ERS research seminar in Rome, Italy, February 11-12 1999. Eur Respir J 2000; 15: 807-815.

184 Skeletal muscle dysfunction in obstructive pulmonary disease. A Statement of the American Thoracic Society and European Respiratory Society. Am J Respir Crit Care Med 1999; 159: 2S-40S.

185 Oga T, Nishimura K, Tsukino M, Sato S, Hajiro T. Analysis of the factors related to mortality in chronic obstructive pulmonary disease: role of exercise capacity and health status. Am J Respir Crit Care Med 2003; 167: 544-549.

186 Hiraga T, Maekura R, Okuda Y, et al. Prognostic predictors for survival in patients with COPD using cardiopulmonary exercise testing. Clin Physiol Funct Imaging 2003; 23: 324-331.

187 Gerardi DA, Lovett L, Benoit-Connors ML, Reardon JZ, ZuWallack RL. Variables related to increased mortality following out-patient pulmonary rehabilitation. Eur Respir J 1996; 9: 431-435.

188 Bowen JB, Votto JJ, Thrall RS, et al. Functional status and survival following pulmonary rehabilitation. Chest 2000; 118: 697-703.

189 Pinto-Plata VM, Cote C, Cabral H, Taylor J, Celli BR. The 6-min walk distance: change over time and value as a predictor of survival in severe COPD. Eur Respir J 2004; 23: 28-33.

190 Celli BR, Cote CG, Marin JM, et al. The body mass index, airflow obstruction, dyspnea, and exercise capacity index in chronic obstructive pulmonary disease. $N$ Engl J Med 2004; 350: 1005-1012.

191 Szekely LA, Oelberg DA, Wright C, et al. Preoperative predictors of operative morbidity and mortality in COPD patients undergoing bilateral lung volume reduction surgery. Chest 1997; 111: 550-558.

192 Geddes D, Davies M, Koyama H, et al. Effect of lungvolume-reduction surgery in patients with severe emphysema. N Engl J Med 2000; 343: 239-245.

193 National Emphysema Treatment Trial Research Group. Cost effectiveness of lung-volume-reduction-surgery for patients with severe emphysema. N Engl J Med 2003; 348: 2092-2102.

194 Kadikar A, Maurer J, Kesten S. The six-minute walk test: a guide to assessment for lung transplantation. J Heart Lung Transplant 1997; 16: 313-319.

195 King TE Jr, Tooze JA, Schwarz MI, Brown KR, Cherniack RM. Predicting survival in idiopathic pulmonary fibrosis: scoring system and survival model. Am J Respir Crit Care Med 2001; 164: 1171-1181.

196 Miki K, Maekura R, Hiraga T, et al. Impairments and prognostic factors for survival in patients with idiopathic pulmonary fibrosis. Respir Med 2003; 97: 482-490. 
197 Miyamoto S, Nagaya N, Satoh T, et al. Clinical correlates and prognostic significance of six-minute walk test in patients with primary pulmonary hypertension. Comparison with cariopulmonary exercise-testing. Am J Respir Crit Care Med 2000; 161: 487-492.

198 Paciocco G, Martinez FJ, Bossone E, Pielsticker E, Gillespie B, Rubenfire M. Oxygen desaturation on the six-minute walk test and mortality in untreated primary pulmonary hypertension. Eur Respir J 2001; 17: 647-652.

199 Kerem E, Reisman J, Corey M, Canny GJ, Levison H. Prediction of mortality in patients with cystic fibrosis. $N$ Engl J Med 1992; 326: 1187-1191.

200 ATS. International guidelines for the selection of lung transplant candidates. Am J Respir Crit Care Med 1998; 158: 335-339.

201 Augarten A, Akons H, Aviram M, et al. Prediction of mortality and timing of referral for lung transplantation in cystic fibrosis patients. Pediat Transplant 2001; 5: 339-342.

202 Sharples L, Hathaway T, Dennis C, Caine N, Higenbottam T, Wallwork J. Prognosis of patients with cystic fibrosis awaiting heart and lung transplantation. $J$ Heart Lung Transplant 1993; 12: 669-674.

203 Nixon PA, Orenstein DM, Kelsey SF, Doershuk CF. The prognostic value of exercise testing in patients with cystic fibrosis. N Engl J Med 1992; 327: 1785-1788.

204 Huang NN, Schidlow DV, Szatrowski TH, et al. Clinical features, survival rate, and prognostic factors in young adults with cystic fibrosis. Am J Med 1987; 82: 871-879.

205 Corey M, McLaughlin FJ, Williams M, Levison H. A comparison of survival, growth, and pulmonary function in patients with cystic fibrosis in Boston and Toronto. $J$ Clin Epidemiol 1988; 41: 583-591.

206 Schwebel C, Pin I, Barnoud D, et al. Prevalence and consequences of nutritional depletion in lung transplant candidates. Eur Respir J 2000; 16: 1050-1055.

207 Stanghelle JK, Hjeltnes N, Michalsen H, Bangstad HJ, Skyberg D. Pulmonary function and oxygen uptake during exercise in 11-year-old patients with cystic fibrosis. Acta Paediatr Scand 1986; 75: 657-661.

208 Hjeltnes N, Stanghelle JK, Skyberg D. Pulmonary function and oxygen uptake during exercise in 16 year old boys with cystic fibrosis. Acta Paediatr Scand 1984; 73: 548-553.

209 Moser C, Tirakitsoontorn P, Nussbaum E, Newcomb R, Cooper DM. Muscle size and cardiorespiratory response to exercise in cystic fibrosis. Am J Respir Crit Care Med 2000; 162: 1823-1827.

210 Stanghelle JK, Skyberg D, Haanaes OC. Eight-year follow-up of pulmonary function and oxygen uptake during exercise in 16-year-old males with cystic fibrosis. Acta Paediatr 1992; 81: 527-531.

211 Moorcroft AJ, Dodd ME, Webb AK. Exercise testing and prognosis in adult cystic fibrosis. Thorax 1997; 52: 291-293.

212 Balfour-Lynn IM, Prasad SA, Laverty A, Whitehead BF, Dinwiddie R. A step in the right direction: assessing exercise tolerance in cystic fibrosis. Pediatr Pulmonol 1998; 25: 278-284.

213 Selvadurai HC, Cooper PJ, Meyers N, et al. Validation of shuttle tests in children with cystic fibrosis. Pediatr Pulmonol 2003; 35: 133-138.
214 Pouessel G, Santos C, Thumerelle C, et al. Reproducibility of the shuttle walk test in children with cystic fibrosis. Rev Mal Respir 2003; 20: 711-718.

215 Aurora P, Wade A, Whitmore P, Whitehead B. A model for predicting life expectancy of children with cystic fibrosis. Eur Respir J 2000; 16: 1056-1060.

216 Cahalin L, Pappagianopoulos P, Prevost S, Wain J, Ginns L. The relationship of the 6-min walk test to maximal oxygen consumption in transplant candidates with end-stage lung disease. Chest 1995; 108: 452-459.

217 Gulmans VA, van Veldhoven NH, de Meer K, Helders PJ. The six-minute walking test in children with cystic fibrosis: reliability and validity. Pediatr Pulmonol 1996; 22: 85-89.

218 Tantisira KG, Systrom DM, Ginns LC. An elevated breathing reserve index at lactate threshold is a predictor of mortality in patients with cystic fibrosis awaiting lung transplantation. Am J Respir Crit Care Med 2002; 165: 1629-1633.

219 Morise AP, Jalisi F. Evaluation of pretest and exercise test scores to assess all-cause mortality in unselected patients presenting for exercise testing with symptoms of suspected coronary artery disease. J Am Coll Cardiol 2003; 42: 842-850.

220 Villella M, Villella A, Santoro L, et al. Ergometric score systems after myocardial infarction: prognostic performance of the Duke Treadmill Score, Veterans Administration Medical Center Score, and of a novel score system, GISSI-2 Index, in a cohort of survivors of acute myocardial infarction. Am Heart J 2003; 145: 475-483.

221 Peterson LR, Schechtman KB, Ewald GA, et al. The effect of beta-adrenergic blockers on the prognostic value of peak exercise oxygen uptake in patients with heart failure. J Heart Lung Transplant 2003; 22: 70-77.

222 O'Neill JO, Young JB, Pothier CE, Lauer MS. Peak oxygen consumption as a predictor of death in patients with heart failure receiving b-blockers. Circulation 2005; 111: 2313-2318.

223 Corra U, Mezzani A, Bosimini E, Giannuzzi P. Cardiopulmonary exercise testing and prognosis in chronic heart failure: a prognosticating algorithm for the individual patient. Chest 2004; 126: 942-950.

224 Gibbons RJ, Balady GJ, Beasley JW, et al. ACC/AHA Guidelines for Exercise Testing. A report of the American College of Cardiology/American Heart Association. Task Force on Practice Guidelines (Committee on Exercise Testing). J Am Coll Cardiol 1997; 30: 260-311.

225 Mancini DM, Eisen H, Kussmaul W, Mull R, Edmunds LH Jr, Wilson JR. Value of peak exercise oxygen consumption for optimal timing of cardiac transplantation in ambulatory patients with heart failure. Circulation 1991; 83: 778-786.

226 Kleber FX, Vietzke G, Wernecke KD, et al. Impairment of ventilatory efficiency in heart failure. Circulation 2000; 101: 2803-2809.

227 Szlachcic J, Massie BM, Kramer BL, Topic N, Tubau J. Correlates and prognostic implication of exercise capacity in chronic congestive heart failure. Am J Cardiol 1985; 55: 1037-1042.

228 Arena R, Myers J, Aslam SS, Varughese EB, Peberdy MA. Peak $\mathrm{V}^{\prime} \mathrm{O}_{2}$ and $\mathrm{V}^{\prime} \mathrm{E} / \mathrm{V}^{\prime} \mathrm{CO}_{2}$ slope in patients with heart 
failure: a prognostic comparison. Am Heart J 2004; 147: 354-360.

229 Arena R, Humphrey R. Comparison of ventilatory expired gas parameters used to predict hospitalization in patients with heart failure. Am Heart J 2002; 143: 427-432.

230 Corra U, Mezzani A, Bosimini E, Scapellato F, Imparato A, Giannuzzi P. Ventilatory response to exercise improves risk stratification in patients with chronic heart failure and intermediate functional capacity. Am Heart J 2002; 143: 418-426.

231 Francis DP, Shamin W, Davies LC, et al. Cardiopulmonary exercise testing for prognosis in chronic heart failure: continuous and independent prognostic value from $\mathrm{V}^{\prime} \mathrm{E} / \mathrm{V}^{\prime} \mathrm{CO}_{2}$ slope and peak $\mathrm{V}^{\prime} \mathrm{O}_{2}$. Eur Heart J 2000; 21: 154-161.

232 Robbins M, Francis G, Pashkow FJ, et al. Ventilatory and heart rate responses to exercise: better predictors of heart failure mortality than peak oxygen consumption. Circulation 1999; 100: 2411-2417.

233 Rostagno C, Olivo G, Comeglio M, et al. Prognostic value of 6-minute walk corridor test in patients with mild to moderate heart failure: comparison with other methods of functional evaluation. Eur J Heart Fail 2003; 5: 247-252.

234 Cahalin LP, Mathier MA, Semigran MJ, Dec GW, DiSalvo TG. The six-minute walk test predicts peak oxygen uptake and survival in patients with advanced heart failure. Chest 1996; 110: 325-332.

235 Shah MR, Hasselblad V, Gheorghiade M, et al. Prognostic usefulness of the six-minute walk in patients with advanced congestive heart failure secondary to ischemic or nonischemic cardiomyopathy. Am J Cardiol 2001; 88: 987-993.

236 Lewis ME, Newall C, Townend JN, Hill SL, Bonser RS. Incremental shuttle walk test in the assessment of patients for heart transplantation. Heart 2001; 86: 183-187.

237 Hill DW. The critical power concept: a review. Sports Medicine 1993; 16: 237-254.

238 Morton $\mathrm{RH}$. The critical power and related whole-body bioenergetic models. Eur J Appl Physiol 2005; 12: 1-16.

239 Poole DC, Ward SA, Gardner GW, Whipp BJ. Metabolic and respiratory profile of the upper limit for prolonged exercise in man. Ergonomics 1988; 31: 1265-1279.

240 Neder JA, Jones PW, Nery LE, Whipp BJ. Determinants of the exercise endurance capacity in patients with chronic obstructive pulmonary disease. The power-duration relationship. Am J Respir Crit Care Med 2000; 162: 497-504.

241 Hill DW, Smith JC. A comparison of methods of estimating anaerobic work capacity. Ergonomics 1993; 36: 1495-1500.

242 Oga T, Nishimura K, Tsukino M, Hajiro T, Ikeda A, Izumi T. The effects of oxitropium bromide on exercise performance in patients with stable chronic obstructive pulmonary disease. A comparison of three different exercise tests. Am J Respir Crit Care Med 2000; 161: 1897-1901.

243 Creutzberg EC, Wouters EF, Mostert R, Pluymers RJ, Schols AM. A role for anabolic steroids in the rehabilitation of patients with COPD? A double-blind, placebocontrolled, randomized trial. Chest 2003; 124: 1733-1742.

244 Redelmeier DA, Bayoumi AM, Goldstein RS, Guyatt GH. Interpreting small differences in functional status: the Six
Minute Walk test in chronic lung disease patients. Am J Respir Crit Care Med 1997; 155: 1278-1282.

245 Ward SA, Whipp BJ. Effects of peripheral and central chemoreflex activation on the isopnoeic rating of breathing in exercising humans. J Physiol 1989; 411: 27-43.

246 Adams L, Guz A. Dyspnea on exertion. In: Whipp BJ, Wasserman K, eds. Excercise: Pulmonary Physiology and Pathophysiology of Exercise. New York, Dekker. 1991; pp. 449-494.

247 Somfay A, Porszasz J, Lee SM, Casaburi R. Doseresponse effect of oxygen on hyperinflation and exercise endurance capacity in nonhypoxemic COPD patients. Eur Respir J 2001; 18: 77-84.

248 Mahler DA, Fierro-Carrion G, Mejia-Alfaro R, Ward J, Baird JC. Responsiveness of continuous ratings of dyspnea during exercise in patients with COPD. Med Sci Sports Exerc 2005; 37: 529-535.

249 Teramoto S, Fukuchi Y, Orimo H. Effects of inhaled anticholinergic drug on dyspnea and gas exchange during exercise in patients with chronic obstructive pulmonary disease. Chest 1993; 103: 1774-1782.

250 O'Donnell DE, Lam M, Webb KA. Spirometric correlates of improvement in exercise performance after anticholinergic therapy in chronic obstructive pulmonary disease. Am J Respir Crit Care Med 1999; 160: 542-549.

251 Ayers ML, Mejia R, Ward J, Lentine T, Mahler DA. Effectiveness of salmeterol versus ipratropium bromide on exertional dyspnoea in COPD. Eur Respir J 2001; 17: 1132-1137.

252 O'Donnell DE, Fluge T, Gerken F, et al. Effects of tiotropium on lung hyperinflation, dyspnoea and exercise tolerance in COPD. Eur Respir J 2004; 23: 832-840.

253 O'Donnell DE, Voduc N, Fitzpatrick M, Webb KA. Effect of salmeterol on the ventilatory response to exercise in chronic obstructive pulmonary disease. Eur Respir J 2004; 24: 86-94.

254 Palange P, Valli G, Onorati P, et al. Effect of heliox on lung dynamic hyperinflation, dyspnea, and exercise endurance capacity in COPD patients. J Appl Physiol 2004; 97: 1637-1642.

255 Casaburi R, Patessio A, Ioli F, Zanaboni S, Donner CF, Wasserman K. Reductions in exercise lactic acidosis and ventilation as a result of exercise training in patients with obstructive lung disease. Am Rev Respir Dis 1991; 143: 9-18.

256 Gosselink R, Troosters T, Decramer M. Physiological adaptations after exercise training in patients with COPD. Am J Respir Crit Care Med 1997; 155: A497.

257 Ries AL, Kaplan RM, Limberg TM, Prewitt LM. Effects of pulmonary rehabilitation on physiologic and psychosocial outcomes in patients with chronic obstructive pulmonary disease. Ann Int Med 1995; 122: 823-832.

258 Wijkstra PJ, van der Mark TW, Kraan J, van Altena R, Koeter GH, Postma DS. Effects of home rehabilitation on physical performance in patients with chronic obstructive pulmonary disease (COPD). Eur Respir J 1996; 9: 104-110.

259 O'Donnell DE, McGuire M, Samis L, Webb KA. General exercise training improves ventilatory and peripheral muscle strength and endurance in chronic airflow limitation. Am J Respir Crit Care Med 1998; 157: 1489-1497.

260 O'Donnell DE, McGuire M, Samis L, Webb KA. The impact of exercise reconditioning on breathlessness in 
severe chronic airflow limitation. Am J Respir Crit Care Med 1995; 152: 2005-2013.

261 Maltais F, Leblanc P, Jobin J, et al. Intensity of training and physiologic adaptation in patients with chronic obstructive pulmonary disease. Am J Respir Crit Care Med 1997; 155: 555-561.

262 Maltais F, Hamilton A, Marciniuk D, et al. Improvements in symptom-limited exercise performance over $8 \mathrm{~h}$ with once-daily tiotropium in patients with COPD. Chest 2005; 128: 1168-1178.

263 Emtner M, Porszasz J, Burns M, Somfay A, Casaburi R. Benefits of supplemental oxygen in exercise training in nonhypoxemic chronic obstructive pulmonary disease patients. Am J Resp Crit Care Med 2003; 168: 1034-1042.

264 Hopkinson NS, Toma TP, Hansell DM, et al. Effect of bronchoscopic lung volume reduction on dynamic hyperinflation and exercise in emphysema. Am J Respir Crit Care Med 2005; 171: 453-460.

265 Casaburi R, Kukafka D, Cooper CB, Witek TJ Jr, Kesten S. Improvement in exercise tolerance with the combination of tiotropium and pulmonary rehabilitation in patients with COPD. Chest 2005; 127: 809-817.

266 Porszasz J, Emtner M, Goto S, Somfay A, Whipp BJ, Casaburi R. Exercise training decreases ventilatory requirements and exercise-induced hyperinflation at submaximal intensities in patients with COPD. Chest 2005; 128: 2025-2034.

267 van 't Hul A, Gosselink R, Kwakkel G. Constant-load cycle endurance performance: test-retest reliability and validity in patients with COPD. J Cardiopulm Rehabil 2003; 23: $143-150$.

268 Maltais F, LeBlanc P, Simard C, et al. Skeletal muscle adaptation to endurance training in patients with chronic obstructive pulmonary disease. Am J Respir Crit Care Med 1996; 154: 442-447.

269 Casaburi R, Storer TW, Wasserman K. Mediation of reduced ventilatory response to exercise after endurance training. J Appl Physiol 1987; 63: 1533-1538.

270 Cambach W, Chadwick-Straver RVM, Wagenaar RC, Van Keimpema AR, Kemper HC. The effects of a communitybased pulmonary rehabilitation programme on exercise tolerance and quality of life: a randomized controlled trial. Eur Respir J 1997; 10: 104-113.

271 Casaburi R, Porszasz J, Burns MR, Carithers ER, Chang RS, Cooper CB. Physiologic benefits of exercise training in rehabilitation of patients with severe chronic obstructive pulmonary disease. Am J Respir Crit Care Med 1997; 155: 1541-1551.

272 Casaburi R, Storer TW, Ben-Dov I, Wasserman K. Effect of endurance training on possible determinants of $\mathrm{VO}_{2}$ during heavy exercise. J Appl Physiol 1987; 62: 199-207.

273 Palange $\mathrm{P}$, Galassetti P, Mannix ET, et al. Oxygen effect on $\mathrm{O}_{2}$ deficit and $V \mathrm{O}_{2}$ kinetics during exercise in obstructive pulmonary disease. J Appl Physiol 1995; 78: 2228-2234.

274 Troosters T, Vilaro J, Rabinovich R, et al. Physiological responses to the 6-min walk test in patients with chronic obstructive pulmonary disease. Eur Respir J2002;20:564-569.

275 Onorati P, Antonucci R, Valli G, et al. Non-invasive evaluation of gas exchange during a shuttle walking test vs. a 6-min walking test to assess exercise tolerance in COPD patients. Eur J Appl Physiol 2003; 89: 331-336.

276 Troosters T, Gosselink R, Decramer M. Short- and longterm effects of outpatient rehabilitation in patients with chronic obstructive pulmonary disease: a randomized trial. Am J Med 2000; 109: 207-212.

277 Spruit MA, Gosselink R, Troosters T, De Paepe K, Decramer M. Resistance versus endurance training in patients with COPD and peripheral muscle weakness. Eur Respir J 2002; 19: 1072-1078.

278 Ries AL, Kaplan RM, Myers R, Prewitt LM. Maintenance after pulmonary rehabilitation in chronic lung disease: a randomized trial. Am J Respir Crit Care Med 2003; 167: 880-888.

279 Paggiaro PL, Dahle R, Bakran I, Frith L, Hollingworth K, Efthimiou J. Multicentre randomised placebo-controlled trial of inhaled fluticasone propionate in patients with chronic obstructive pulmonary disease. International COPD Study Group. Lancet 1998; 351: 773-780.

280 McKelvie RS, Teo KK, Roberts R, et al. Effects of exercise training in patients with heart failure: the Exercise Rehabilitation Trial (EXERT). Am Heart J 2002; 144: 23-30.

281 Griffiths TL, Burr ML, Campbell IA, et al. Results at 1 year of outpatient multidisciplinary pulmonary rehabilitation: a randomised controlled trial. Lancet 2000; 355: 362-368.

282 Wedzicha JA, Bestall JC, Garrod R, Garnham R, Paul EA, Jones PW. Randomized controlled trial of pulmonary rehabilitation in severe chronic obstructive pulmonary disease patients, stratified with the MRC dyspnoea scale. Eur Respir J 1998; 12: 363-369.

283 Wadbo M, Lofdahl CG, Larsson K, et al. Swedish Society of Respiratory Medicine. Effects of formoterol and ipratropium bromide in COPD: a 3-month placebocontrolled study. Eur Respir J 2002; 20: 1138-1146.

284 Pepin V, Saey D, Whittom F, Leblanc P, Maltais F. Walking versus cycling: sensitivity to bronchodilation in chronic obstructive pulmonary disease. Am J Respir Crit Care Med 2005; 172: 1517-1522.

285 Revill SM, Morgan MD, Singh SJ, Williams J, Hardman AE. The endurance shuttle walk: a new field test for the assessment of endurance capacity in chronic obstructive pulmonary disease. Thorax 1999; 54: 213-222.

286 Spence DP, Hay JG, Carter J, Pearson MG, Calverley PM. Oxygen desaturation and breathlessness during corridor walking in chronic obstructive pulmonary disease: effect of oxitropium bromide. Thorax 1993; 48: 1145-1150.

287 Leach RM, Davidson AC, Chinn S, Twort CH, Cameron IR, Bateman NT. Portable liquid oxygen and exercise ability in severe respiratory disability. Thorax 1992; 47: 781-789.

288 Davidson AC, Leach R, George RJ, Geddes DM. Supplemental oxygen and exercise ability in chronic obstructive airways disease. Thorax 1988; 43: 965-971.

289 Garrod R, Paul EA, Wedzicha JA. Supplemental oxygen during pulmonary rehabilitation in patients with COPD with exercise hypoxaemia. Thorax 2000; 55: 539-543.

290 Revill SM, Singh SJ, Morgan MD. Randomized controlled trial of ambulatory oxygen and an ambulatory ventilator on ecndurance exercise in COPD. Respir Med 2000; 94: 778-783.

291 Harbour R, Miller J. A new system for grading recommendations in evidence based guidelines. BMJ 2001; 323: 334-336. 